\title{
Genomic MET amplification occurs early in NF1-related malignant peripheral nerve sheath tumor (MPNST) progression and is a potent therapeutic target
}

Jacqueline D. Peacock ${ }^{1}$, Matthew G. Pridgeon ${ }^{2}$, Elizabeth A. Tovar ${ }^{1}$, Curt J. Essenburg ${ }^{1}$, Megan Bowman $^{3}$, Zachary Madaj ${ }^{3}$, Julie Koeman ${ }^{4}$, Jamie Grit ${ }^{1}$, Rebecca D. Dodd ${ }^{5}$, Diana M. Cardona ${ }^{6}$, Mark Chen ${ }^{5}$, David G. Kirsch ${ }^{5,7}$, Flavio Maina ${ }^{8}$, Rosanna Dono ${ }^{8}$, Mary E. Winn ${ }^{3}$, Carrie R. Graveel $^{1}$, and Matthew R. Steensma ${ }^{1,2,9}$

${ }^{1}$ Center for Cancer and Cell Biology, Van Andel Research Institute, Grand Rapids, MI, USA ${ }^{2}$ Helen DeVos Children's Hospital, Spectrum Health System, Grand Rapids, MI, USA ${ }^{3}$ Bioinformatics and Biostatistics Core, Van Andel Research Institute, Grand Rapids, MI ${ }^{4}$ Genomics Core, Van Andel Research Institute, Grand Rapids, MI, USA ${ }^{5}$ Department of Radiation Oncology, Duke University Medical Center, Durham, NC, USA. ${ }^{6}$ Department of Pathology, Duke University Medical Center, Durham, NC, USA ${ }^{7}$ Department Pharmacology and Cancer Biology, Duke University Medical Center, Durham, NC, USA.

${ }^{8}$ Aix-Marseille Université, CNRS, IBDM, Marseille, France

${ }^{9}$ Michigan State University College of Human Medicine, Grand Rapids, MI, USA

Running Title: MET amplification promotes NF1-related MPNST progression

Keywords: malignant peripheral nerve sheath tumor (MPNST), NF1, MET, mouse model, capmatinib

Funding: The Neurofibromatosis Therapeutic Acceleration Program (NTAP), The Johns Hopkins University (JHU), and the Van Andel Institute.

Conflict of interest: The authors have declared that no conflict of interest exists.

Word Count: 5092

Figures: 6

Supplemental Data: 6 Tables, 2 Figures, Supplemental Methods

\section{Corresponding Author:}

Matthew Steensma

333 Bostwick Ave. NE

Grand Rapids MI, 49503

Matt.Steensma@vai.org

Phone: 616-234-5378

Fax: 616-234-5721 


\begin{abstract}
Malignant Peripheral Nerve Sheath Tumors (MPNSTs) are highly resistant sarcomas that occur in up to $13 \%$ of individuals with Neurofibromatosis Type 1 (NF1). Genomic analysis of longitudinally collected tumor samples in a case of MPNST disease progression revealed early hemizygous microdeletions in NF1 and TP53, with concomitant amplifications of MET, HGF, and EGFR. To examine the role of MET in MPNST progression, we developed mice with enhanced MET

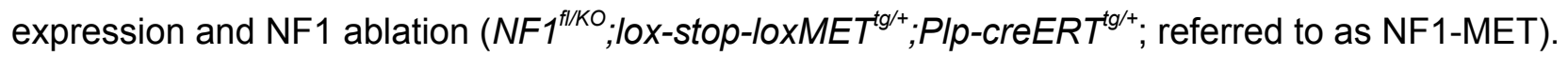
NF1-MET mice express a robust MPNST phenotype in the absence of additional mutations. A

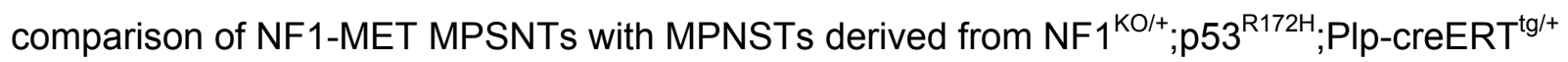
(NF1-P53) and $\mathrm{NF}^{\mathrm{KO} /+} ; \mathrm{Plp}-\mathrm{CreERT}^{\mathrm{tg} /+}$ (NF1) mice revealed unique Met, Ras, and PI3K signaling patterns. To investigate the therapeutic potential of MET inhibition among tumorgrafts derived from the respective MPNST models, we tested the highly selective MET inhibitor, capmatinib. NF1-MET MPNSTs were uniformly sensitive to MET inhibition whereas only a small subset of NF1-P53 and NF1 MPNSTs were inhibited. These results confirm that MET activation is sufficient for Schwann cell dedifferentiation into MPNSTs in the context of NF1 deficiency. RAS-MET signal interactions may be an important driver of MPSNT disease progression.
\end{abstract}




\section{Introduction}

Neurofibromatosis type 1 (NF1) is caused by germline mutations in the NF1 gene and is the most common single-gene disorder affecting $\sim 1$ in 3,000 live births (1,2). Approximately $8-13 \%$ of individuals with NF1 will develop malignant tumors, most commonly Malignant Peripheral Nerve Sheath Tumors (MPNSTs) (3). NF1-related MPNSTs are highly aggressive sarcomas that frequently metastasize and have five-year survival rates ranging from $20-50 \%$ (4-8). The mainstay of treatment is surgical resection when possible with consideration of chemotherapy and radiation therapy in select cases. Even though chemotherapy may initially stabilize disease, early responses are typically followed by a rapid evolution of chemoresistance and metastasis (9).

The NF1 gene encodes neurofibromin, a GTPase-activating protein that regulates RAS (including HRAS, NRAS, and KRAS) and loss of NF1 leads to deregulated RAS signaling. The RAS signaling node activates multiple kinase effector cascades, including the RAF-MEK-ERK pathway. NF1-related MPNSTs have been shown to arise from NF1-null myelinating Schwann cells where neurofibromin deficiency results in RAS deregulation (1015). Plexiform neurofibromas are the benign precursor of NF1-related MPNSTs and are formed by a recruited admixture of NF1 haploinsufficient cells (fibroblasts, mast cells, and perineurial cells) following an initial NF1-loss-of-heterozygosity event in a peripheral nerve Schwann cell (16-18). A variety of genomic alterations have been observed in the malignant transformation of benign plexiform neurofibromas into MPNSTs including deleterious mutations that impact cell cycle regulation (CDKN2A), apoptosis (TP53), tumor suppression (PTEN, RASSF1A) and chromatin modification (SUZ12/PRC2 gene family) (19-21). Genes encoding receptor tyrosine kinase (RTKs) and their putative ligands are also amplified in MPNSTs, including MET, HGF, EGFR, ERBB2, PDGFRa, and c-Kit. NF1-related MPNSTs exhibit significant intertumoral heterogeneity, and it is difficult to determine the relative impact of common MPNST genomic alterations on disease progression and therapeutic response 
$(22-24)$.

The oncogene MET encodes a receptor tyrosine kinase that is involved in the progression and metastasis of most solid human cancers (25-27). The pleiotropic effects of MET activation are mediated through a variety of effector pathways including dominant regulators of cellular proliferation and survival (i.e. RAS/ERK, PI3K/AKT/mTOR) and cellular motility (STAT3, Rho kinases. Several studies have implicated oncogenic MET signal activation in NF1-related MPNST disease progression. An increase in MET expression has been observed in the malignant transformation of plexiform neurofibromas into MPNSTs (28). Furthermore, high-resolution array-CGH recently identified MET and HGF gene amplifications in a significant proportion ( 30\%) of NF1-related MPNSTs (24). MET phosphorylation (Tyr1234/35) was demonstrated in at least half of MPNSTs, and was recently proposed as a biomarker for MET-activated MPNSTs (29). In this same study, inhibition of MET/NEGFR2/RET (cabozantinib) mitigated tumor growth in an MPNST xenograft model. Currently, it is unclear 1) whether MET activation is sufficient for malignant transformation of NF1-deficient Schwann cells to into MPNSTs, and 2) how the RAS and MET signaling pathways interact in MPNSTs.

Here, we used a longitudinal genomic analysis to identify key genetic events underlying transformation of a plexiform neurofibroma to MPNST. Our results indicate that there is positive selection for MET and HGF copy number gain early in MPNST progression that precedes accumulation of other oncogene amplifications and additional losses of tumor suppression gene function. In order to interrogate the role of MET signaling in MPNST progression and therapy response, we developed and characterized a unique mouse model of MET activation in p53 wild type, NF1-null myelinating cells. Our hypothesis is that MET activation is sufficient to drive malignant tumorigenesis when combined with putative NF1 loss of function, and that MET-activated MPNSTs will respond to targeted MET inhibition. Our findings build upon prior work examining NF1 loss of heterozygosity ( $\mathrm{LOH}$ ) in myelinating cells 
$(30,31)$ and present a complementary model of MPNST to established models combining NF1 loss with p53 or Ink4a/Arf $(19,32)$. Our results demonstrate that highly selective MET inhibition is effective against MPNSTs bearing a "MET addicted" signature whereby MET inhibition also mitigates downstream RAS-ERK and PI3K-AKT activation. Conversely, we show reduced effectiveness of MET inhibitor monotherapy in Met-amplified NF1-P53 and Hgf-amplified NF1 MPNSTs. These findings are attributable in part to signaling adaptations that occur early during therapy. These results expand our current understanding of the role of MET signaling in MPNST disease progression and identify a potential therapeutic niche for NF1-related MPNSTs. Moreover, these findings highlight the influence of co-occurring genomic alterations on RAS effector signaling and therapy response to tyrosine kinase inhibitors. 


\section{Results}

Longitudinal genomic analysis of MPNST progression confirms progressive genomic instability

To investigate the genomic alterations that occur during MPNST progression, we followed the disease course of an NF1-affected adolescent male who developed a high grade, metastatic MPNST arising from a chest wall plexiform neurofibroma. Exome sequencing was performed on biopsies procured throughout disease progression: benign plexiform neurofibroma $\rightarrow$ MPNST pretreatment $\rightarrow$ MPNST posttreatment $\rightarrow$ MPNST metastasis (Figure 1A). The patient initially presented at 15 years of age with a rapidly enlarging mass in his left axilla that measured $11 \times 9 \times$ $17 \mathrm{~cm}$ by MRI (Figure 1B, left panel). Biopsies were performed at diagnosis which verified the presence of a high grade MPNST arising within a plexiform neurofibroma (AJCC stage 3, $\mathrm{T}_{2} \mathrm{bG}_{3} \mathrm{NoM}_{0}$ ). The patient received neoadjuvant chemotherapy consisting of 3 cycles of ifosfamide and doxorubicin. To enhance the resectability of the tumor following neoadjuvant chemotherapy, the patient received 5000 cGy of preoperative radiation concurrently with two further cycles of ifosfamide. The combined radiation and chemotherapy reduced the size of the tumor enough to permit wide resection with chest wall reconstruction four months after diagnosis Figure $1 \mathrm{~B}$, middle panel). Following resection, the patient completed two additional cycles of chemotherapy with ifosfamide and doxorubicin. Surveillance imaging obtained four months after the end of therapy revealed recurrent disease in both lungs (Figure 1B, right panel) and CT-guided biopsy confirmed the diagnosis of metastatic MPNST. The recurrence was not amenable to resection and the patient succumbed to disease two years from the date of original diagnosis

To evaluate the genomic alterations that occurred during MPNST progression in this case, tumor DNA was analyzed using a shotgun whole exome sequencing approach. Copy number alterations were inferred using TITAN with the patient's peripheral blood DNA serving as a normal control. The genomic alterations that were identified in each stage of MPNST progression are summarized in a Circos plot (Figure 1C). As expected, the plexiform neurofibroma DNA had few copy number variations (ring a, Figure 1C), but the pre-treatment MPNST demonstrated 
chromosomal amplifications (orange regions) on chromosomes 1, 7, and 8 (ring b, Figure 1C). These amplifications were maintained throughout the remaining disease progression. Additional structural alterations and site-specific amplifications accumulated throughout the course of treatment (ring c, Figure 1C). Regional amplifications on chromosome (chr) 5, chr15, a potential whole chromosomal amplification of chr7, and deletion of chr16 (ring a, Figure 1C) developed in the metastatic lesion, specifically. Several deletions (green) were also identified in the MPNST, including a region of chr17q that contains TP53 and NF1. Notably, the deleted regions of chr17q as well as regions on chr3, chr6, and chr16 progressively expanded throughout disease progression. Focused analysis of known MPNST-related loci $A E B P 2, C D K N 2 A, C D K N 2 D, C H D 4$, EED, EGFR, EPC1, EZH2, HGF, MET, NF1, PTEN,RASSF1, SUZ12, and TP53 was performed (Figure 1D). The SUZ12 locus was found to be altered in the plexiform neurofibroma, within a genomic segment that while diploid, is representative of a near loss of heterozygosity event on chromosome 17. Somatic mutations in SUZ12 were not observed, but a single germline intron variant was identified. Therefore, the near loss of heterozygosity is representative of a potential genomic structural change within the SUZ12 region of chromosome 17 . The observed structural alterations appear to be nonrandom and favor gain of oncogenic receptor tyrosine kinases and loss of TP53.

The earliest observed genomic alterations in the MPNST were balanced copy number gains in MET, HGF, EGFR, and to a lesser degree amplification of CDKN2D. Changes in these specific loci preceded other sites of additional oncogene amplification or tumor suppressor loss. The number of amplified MET, HGF, and EGFR loci continued to increase during MPNST progression (Figure 2A). Specifically, the copy numbers of $M E T, H G F$, and EGFR progressed from a balanced conformation relative to ploidy state in the pre-treatment MPNST, to an imbalanced amplification above regional ploidy state in the recurrent MPNST (Figure 1D, Figure 2A). MET copy number gain was confirmed in the pretreatment and recurrent MPNST using quantitative copy number PCR (Supplemental Figure 1). Loss of NF1 and TP53 was also 
observed in the pre-, post- and recurrent-MPNST samples (Figure 1D, Figure 2B). Interestingly, the non-synonymous coding alteration in the TP53 gene, NC_000017.11:g.7673223G>C, was found to be present in combination with TP53 hemizygosity in all stages of the MPNST. A similar phenomenon was observed for a synonymous coding mutation at the hemizygous $C D K N 2 A$ locus in the metastatic tumor. Copy neutral loss of heterozygosity events were observed in the posttreatment sample in the genes CHD4, EED, EPC1, PTEN, and RASSF1. These observations demonstrate an important role for MET and HGF in the earliest stages of MPNST disease progression.

Met amplification and NF1 loss in peripheral nerve myelinating cells is sufficient to induce MPNST formation

To interrogate the role of MET activation in NF1-related MPNSTs, we developed a mouse model that reflects MET amplification in the context of NF1 deficiency. In this Cre-inducible mouse model (Figure 3A), a humanized MET transgene that was previously shown to activate MET signaling above physiologic thresholds in neuronal tissue $(33,34)$ was combined with NF1 deficiency in myelinating Schwann cells $(30,35)$. These two genetic events were induced immediately after birth using a tamoxifen-inducible Plp-creERT transgene (36) in mice with a global, constitutive loss of the NF1 allele. Tamoxifen induction at postnatal days 1-5 was selected to best replicate plexiform neurofibromagenesis based on previous studies of $N F 1^{f / K O} ; P l p-c r e E R T^{t g /+}$ mice $(30,31)$. Allele-specific PCR confirmed recombination of the loxp-flanked NF1 gene in peripheral nerves and the presence of the recombined Met transgene (Figure 3B). For brevity we refer to the $N F 1^{f / K o} ; / O x$-stop-loxME $T^{t g /+} ; P I p-c r e E R T^{t g /+}$ mice as NF1-MET mice throughout the manuscript. NF1-MET mice and controls $\left(\mathrm{NF} 1^{f / K O}\right.$;Cre, $\mathrm{NF} 1^{f / /} ; \mathrm{Met} ; \mathrm{Cre}$, and wild-type) were aged for up to 600 days to evaluate their tumor phenotypes. The tumor free survival of NF1-MET mice was significantly decreased relative to the other four mouse lines (all FDR $q<0.001$, Figure 3C and Supplemental Table 1). The odds of NF1-MET mice being euthanized due to tumor burden was 14.58 times higher than $N F 1^{f / K O}$;Cre mice (FDR 
$q=0.0008,95 \% \mathrm{Cl}[3.51,60.59])$ and 23.33 times higher than $N F 1^{f / / K O}(F D R q=0.0008,95 \% \mathrm{Cl}$ $[4.1,132.9])$ (Supplemental Table 2).

In total, $70 \%$ of NF1-MET mice developed neoplasms, $50 \%$ of which were MPNSTs; whereas in the $13 \%$ of control mice that developed neoplasms, none were MPNSTs (Figure $3 \mathrm{C}$ ). MPNSTs derived from NF1-MET demonstrated the characteristic spindle cell morphology with a fascicular growth pattern (Figure 3D-E). Tumors were classified as MPNSTs according to the established Genetically Engineered Mouse (GEM) nerve-sheath tumor classification: Grade III, S100+/MyoD- with nuclear atypia, high mitotic rate, and focal necrosis or hemorrhage (Figure 3E)(37). Paralysis or pseudo-paralysis of the hind-limbs, occurring in 8 of 29 NF1-MET mice, was another major cause of premature euthanasia (Figure 3D, dark grey bars). Tumor initiation occurred earlier in NF1-MET mice than the other four mouse lines (all FDR $q<0.0001$, Supplemental Table), with a median tumor-free survival time of 438 days (95\% Cl $[408,559])$. Tumors from mice with activated MET transgene expression demonstrated a high rate of cellular proliferation (Ki67) and greater amounts of active phospho-MET (pMET) by immunohistochemistry (Figure 3E).

In order to evaluate MET signaling in other genomic contexts, we isolated MPNSTs from both $N F 1^{K O /+} ; p 53^{L S L-R 172 H}$ and $N F 1^{f / K O} P I p-c r e E R T^{t g /+}$ mice. $N F 1^{K O /+} ; p 53^{L S L-R 172 H}$ mice (referred to as NF1-P53) were derived by crossing the $N F 1^{K O /+}$ and $p 53^{L S L-R 172 H}$ mice (38). These mice did not require crossing with a Cre recombinase for tumor induction, since they are essentially a $p 53^{\mathrm{KO} /+}$ model as the LSL cassette prevents expression of the $p 53^{R 172 H}$ mutant. MPNST tumors from NF1-P53 mice have LOH of the wildtype P53 allele and we confirmed that $p 53^{L S L-R 172 H}$ is in cis with NF1 on Chr11. As a control for NF1 deficiency alone, we aged NF1 $1^{f / K O ;} P l p-c r e E R T^{t g /+}$ mice and isolated an MPNST. For simplicity these mouse lines are referred to as NF1 throughout the manuscript. Immunostaining of the NF1 MPNST showed less activated MET and ERK compared to the NF1-MET MPNST (Figure 3E). 


\section{Copy number gains of MET and HGF observed in murine MPNSTs}

Fluorescence in situ hybridization (FISH) was used to evaluate the Rosa26-targeted MET transgene, the endogenous mouse Met gene, and the endogenous mouse Hgf gene. Confirmation of the transgene was performed with a R26-MET probe in NF1-MET mice. In normal spleen from a NF1-MET mouse, we observed 2-4 copies of the MET transgene and in MPNSTs we observed 2-8 MET transgene copies (Supplemental Figure 2 and Supplemental Table 3). We also performed FISH analysis to determine whether endogenous Met or Hgf were amplified in the MPNST tumors from the various NF1 mouse lines. We did not observe any additional endogenous mouse Met copy number gains in NF1-MET tumors (Figure 4A, Supplemental Table 4).

Conversely, the NF1-P53 MPNST had a Met copy number gain of 2 in $50 \%$ of cells and the NF1 MPNST had a single $\mathrm{Hgf}$ copy number gain in $13 \%$ of MPNST cells (Figure 4B-C, Supplemental Table 4). To ensure the robustness of these models, each founder and the derived tumors were sequenced to verify both induced and spontaneous mutations.

Additional genomic characterization of these NF1-MET mouse tumors, as well as tumors from control MPNSTs in NF1 and NF1-P53 mice was performed using 15-20x whole exome sequencing with the Agilent SureSelectXT2 mouse exome platform. Variants were crossreferenced against a list of genes with demonstrated roles in MPNST disease progression. No additional functional variants were detected in the NF1-MET, NF1, and NF1-P53 mouse models apart from the engineered genomic modifications. In summary, we observed endogenous Met or Hgf copy number gains in the NF1-P53 and NF1 tumors; however the NF1-MET MPNSTs had 4-10 copies of Met (transgene and endogenous Met) and represent a novel model of Met-amplified NF1-related MPNSTs.

\section{Differential kinome response to MET inhibition in murine MPNSTs}

NF1 loss results in dysregulation of RAS-RAF-MEK signaling; however, studies in melanoma have demonstrated that NF1 has RAF-independent signaling activity (39). To 
investigate the effects of NF1 loss, MET activation, and P53 mutation in our MPNST models, we isolated stable cell lines from MPNSTs in NF1-MET, NF1-P53, and NF1 mouse lines. To examine the effects of MET inhibition on kinase signaling within each MPNST line, we used the kinase inhibitor capmatinib. Capmatinib (INC280) is an oral, highly selective and potent MET inhibitor that is well tolerated and has shown clinical activity in advanced solid tumors (40-42). Phase I and II clinical trials are ongoing to investigate the efficacy of capmatinib in cancers including melanoma, HCC, NSCLC, glioblastoma, colorectal cancer, and papillary renal cancer. To evaluate the effects of MET inhibition on downstream signaling in our distinct MPNST lines, we stimulated MET activation with HGF treatment and then treated with capmatinib (Figure 5). MET expression and activation was significantly higher in NF1-MET MPNST cells and required 5 nM INC280 to completely inhibit MET activation (Figure 5, left panel) whereas induced MET activation was eliminated with $1 \mathrm{nM}$ INC280 in both the NF1-P53 and NF1 MPNST cells (Figure 5, middle and right panels). Only in the NF1-MET cells was ERK activation significantly inhibited by capmatinib, where in NF1-P53 and NF1 MPNST cells, ERK activation was marginally reduced by capmatinib treatment. Interestingly, HGF induced strong AKT phosphorylation in the NF1-P53 and NF1 cells (Figure 5, middle and right panels), yet in the NF1-MET cells AKT is highly expressed but minimally activated by HGF. When treated with 1-5 nM capmatinib, AKT activation is shut down in the NF1-MET and NF1 cells, but in the NF1-P53 cells pAKT is unaffected by MET inhibition. Each NF1 MPNST model has varying levels of MET activation that correspond with their sensitivity to MET inhibition. Our results suggest that NF1-depleted cells with MET amplification are highly dependent on MET and RAS/ERK signaling and AKT is likely not a signaling node of resistance. Interestingly, the increased AKT activation in capmatinib-treated NF1-P53 cells suggests this may be a unique mechanism of resistance to RTK inhibition in MPNSTs harboring P53 loss or mutation. Therefore, MET inhibition may be an effective therapeutic strategy when a state of MET-addiction exists. 


\section{NF1-MET MPNST tumorgrafts are exquisitely sensitive to MET inhibition}

Because MET is constitutively active in NF1-MET MPNSTs as compared to NF1-P53 and NF1 MPNSTs, we aimed to determine the effect of the MET inhibitor capmatinib on in vivo tumor growth. Tumorgrafts were established in immunocompromised mice from primary MPNSTs in the NF1-MET, NF1, and NF1-P53 models. Allele-specific PCR confirmed maintenance of the recombined NF1 gene and Met transgene. We tested the efficacy of three different concentrations of capmatinib $(3,10$, and $30 \mathrm{mg} / \mathrm{kg})$ on MPNST tumor growth. Capmatinib significantly inhibited tumor growth in the NF1-MET-derived tumorgraft model (Figure 6A-B, top panel). Once daily $3 \mathrm{mg} / \mathrm{kg}$ capmatinib significantly reduced the tumor growth rate by an average of $54.3 \mathrm{~mm}^{3} /$ day $(F D R q<0.001,95 \% \mathrm{Cl}[29.7,78.9])$ and $10 \mathrm{mg} / \mathrm{kg}$ dosage further reduced growth rates by an average of $56.1 \mathrm{~mm}^{3} /$ day $(F D R q<0.001,95 \% \mathrm{Cl}[34.0,78.3])$. Increasing the dose to $30 \mathrm{mg} / \mathrm{kg}$ did not produce a significant reduction, but did produce a more consistent effect (Figure 6A). By examining the individual growth curves for each tumor in the treatment compared to vehicle control groups, we assessed the variability in treatment response. The standard deviation of the $30 \mathrm{mg} / \mathrm{kg}$ dosage at 10 days was 181.5 , compared to 228.4 for the $10 \mathrm{mg} / \mathrm{kg}$ treated mice and 465.6 for the vehicle treated mice (Figure 6A, top panel).

Capmatinib treatment of NF1 (Figure 6A-B, middle panel) and NF1-P53 (Figure 6A-B, bottom panel) MPNSTs did not show a significant response due to the heterogeneous treatment response; however in both the NF1-P53 and NF1 lines, we did observe a small subgroup of tumorgrafts that responded to $30 \mathrm{mg} / \mathrm{kg}$ capmatinib. The use of non-parametric bootstrap resampling revealed significant evidence that $30 \mathrm{mg} / \mathrm{kg}$ capmatinib reduced growth of NF1 tumors by an estimated 34.9\% (Figure 6C, Bootstrap 95 percentile interval [7.62, 58.16]; Supplemental Table 4). Non-parametric bootstrapping also showed that capmatinib had the largest effect on NF1-MET MPNSTs with an almost 90\% reduction in tumor growth rate relative to vehicle treatment (Figure 6C, Bootstrap 95 percentile interval Cl [72.7, 102.7]; Supplemental Table 5). These results demonstrate the significant efficacy of MET inhibition in NF1-related MPNSTs with 
high MET expression and activity. Moreover, the results of capmatinib treatment in the NF1-P53 and NF1 lines suggest that MET inhibition is effective in reducing growth rate in a subset of tumors, yet combination therapy may be a more effective approach in MPNSTs with these genomic backgrounds. 


\section{Discussion}

The lack of effective therapies for MPNSTs remains a significant issue for individuals affected by NF1 (5-8). Our purpose in examining the evolution of genomic alterations in the case of a single, NF1-related human MPNST is twofold. Our first objective was to determine the degree of genomic instability that occurs over the course of MPNST treatment following malignant transformation. Intertumoral genomic heterogeneity is well documented in NF1-related MPNSTs $(19,20,23,24,43)$, however expression profiling studies do not necessarily support molecular subtyping at the expression level (23). One theory is that an initial catastrophic event drives somatic and structural variation around the time of malignant transformation, but the genome remains relatively fixed over time. Evidence supporting this idea can be found in the characterization of human MPNST PDX models that demonstrate consistent genomic stability throughout expansion and engraftment (44). Our second objective was to identify targetable drivers of disease progression in MPNSTs. Somatic and structural variants that appear early and accumulate throughout disease progression represent de facto driver mechanisms and in the case of NF1-related MPNSTs, could indicate fundamentally important signaling pathways in Schwann cell dedifferentiation $(45,46)$. Both findings may highlight susceptible pathways or biomarkers for drug targeting.

In our analysis, we identify in the pre-treatment specimen hemizygous microdeletions in the NF1 and TP53 loci, with concomitantly observed amplifications of MET, HGF, and EGFR. It is not surprising that a TP53 variant was present in the pre-treatment MPNST given the prevalence of $P 53$ mutations in clinical samples (47), and the known driver effects of $P 53$ in the context of NF1 deficiency (48); however, the early concomitant presence of $M E T, H G F$, and EGFR amplifications, and the site-specific expansion of these loci over the course of treatment points to an adaptive mechanism for both malignant transformation and clonal selection. The relationship between $P 53$ haploinsufficiency and EGFR amplification has been previously demonstrated in human MPNSTs (49); however the timing and the relationship between MET/HGF and P53 
genomic status has not been evaluated. Direct cooperation between MET and RAS has been shown to promote tumor resistance in other cancers. For example, KRAS and MET amplification mediates acquired resistance to MET inhibitors in MET-addicted gastric and lung cancer cells (50). In an esophagogastric cancer patient treated with a MET inhibitor, a KRAS mutation was discovered as a novel cause of acquired resistance (51). Whereas in KRAS-addicted cancer cells, KRAS mediated MET expression via increased MET translation and promoted "KRas addiction" in anchorage-independent conditions (52). Given the pleiotropic effects of MET activation $(25,26)$ and its emerging role in therapy resistance (53-56), these data provide strong rationale for further exploration of MET-RAS and RAS-MET signal interactions in NF1-related MPNSTS.

Even though therapeutically targeting RTKs has been successful in other cancers, the failure of EGFR inhibition (erlotinib) in MPNSTs indicates that other RTK pathways should be evaluated (57). We hypothesized that MET activation is an early and sufficient event for malignant transformation in NF1-related MPNSTs, and a bona-fide therapeutic target in a subset of "MET-addicted" MPNSTs. To interrogate the role of MET activation in NF1-related MPNSTs, we developed a novel mouse model that reflects MET activation in the context of NF1-deficient Schwann cells. In addition to plexiform neurofibroma formation, NF1-MET mice express a robust MPNST phenotype in the absence of additional spontaneous or induced mutations. An interesting observation is that MPSNT tumorgrafts derived from NF1-P53 mice exhibit spontaneous Met amplification and MPNST tumorgrafts derived from NF1 mice exhibit spontaneous $H g f$ amplification. FISH analysis revealed Met and Hgf copy number variation within tumors supporting the concept that locus-specific instability exists in murine MPNSTs. Despite the presence of Met and $\mathrm{Hgf}$ amplifications respectively, there was no evidence of constitutive MET activation in the NF1-P53 or NF1 models, whereas the NF1-MET tumors were strongly activated at baseline. MET activation was further induced with HGF treatment in all of MPNST tumorgraft cell lines. Collectively, these data confirm that the degree of MET activation is dependent on the 
genomic context and that MET activation is sufficient for malignant transformation in NF1deficient Schwann cells to MPNSTs in the setting of germline NF1 haploinsufficiency.

To investigate the therapeutic potential of MET inhibition among our series of genomically diverse tumorgraft models, we chose the highly selective MET inhibitor, capmatinib which is currently being tested in the setting of EGFR therapy resistance in NSCLC. We demonstrate that MET-activated (NF1-MET) MPNSTs were uniformly sensitive to capmatinib therapy whereas Metamplified NF1-P53 and Hgf-amplified NF1 tumors were only partially inhibited due to response heterogeneity within individual treatment groups. These data represent the first demonstration of capmatinib treatment response in NF1-related MPNSTs. It follows that when MET activation occurs a priori, the subsequently derived MPNSTs exhibit a MET-addicted signature whereby both RAS-ERK and PI3K-AKT activation are completely suppressed by selective MET inhibition. These findings further support the concept that MET inhibition is a viable treatment option for the subset of MPNSTs bearing a MET-addicted signature. Currently, it is difficult to define the size or makeup of the "MET-addicted" clinical subset in the NF1 population due to the lack of suitable biomarkers, however MET Y1234/35 phosphorylation has been proposed as a candidate immunohistochemical marker to define MET-activated MPNSTs, and predict MET inhibitor response (29).

As discussed previously, we observed a heterogeneous treatment response to capmatinib in the NF1-P53 and NF1 tumor groups. One explanation for this partial response is that MPNSTs maintain a fundamental plasticity for reprogramming of RAS effector kinase signaling in the setting of MET inhibition similar to what is observed in breast, lung, and gastric cancers (62-66). The majority of RTKs drive RAS/ERK and PI3K/AKT/mTOR signaling therefore resistance to MET inhibition may be mediated through alternative RTKs that are recruited to support RAS/ERK and PI3K/AKT signaling such as EGFR, PDGFR or both. Alternatively, the emergence of secondary genomic alterations could also drive selection of resistant cell populations. In the NF1-P53 murine MPNST model, EGFR overexpression occurs as a result of locus-specific amplification (58). 
EGFR amplification could partially mitigate response to capmatinib similar to what is observed in MET-addicted gastric carcinoma cells treated with MET inhibitors (59). We show that HGFinducible MET activation is fully inhibited by capmatinib in all tumor models; however, persistence of downstream RAS/MAPK and PI3K/AKT activation occurred in both the NF1-P53 and NF1 models in the setting of complete MET inhibition. Both ERK and AKT activation persisted or was even amplified at the highest concentrations of capmatinib as a result of increased protein synthesis to sustain phosphorylation-dependent activation. These results suggest that the modulation of capmatinib response was dependent on the genomic context of the models. In our companion study Pridgeon et al., we examined how the genomic status of MET and P53 affects the efficacy and kinome response of kinase inhibitors in MPNSTs (60). Overall, these results highlight the challenges of treating genomically diverse MPNSTs with single agent tyrosine kinase inhibition strategies, as well as highlight the diverse mechanisms that promote MPNST progression and therapy resistance. 


\section{Methods}

\section{Whole genome exome sequencing and TITAN analysis}

Extracted DNA samples for both human and mouse were prepared using Agilent SureSelect library prep with the Agilent SureSelect Human All Exon V5 and Agilent SureSelectXT2 exome capture systems, respectfully. Both human and mouse exome samples were sequenced with 2 X 100bp reads on the Illumina HiSeq 2500 from the Michigan State University Research Technology Support Facility (MSU-RTSF) with a total mean read coverage of 50-90X and 15- 20X, respectively. Read quality was assessed using FASTQC (http://www.bioinformatics.bbsrc.ac.uk/projects/fastqc/) and trimmed using seqtk (https://github.com/lh3/seqtk). After trimming, reads were mapped to the hg19 genome using BWAMEM v 0.7.12 (http://arxiv.org/abs/1303.3997) and duplicates were removed with Picard MarkDuplicates (http://broadinstitute.github.io/picard/). Variant calling using the deduplicated BAMs was completed using GATK Best Practices with suggested default values (61-63).

Somatic variants were identified using MUTECT2 (64) using default settings. Copy number alterations (CNA) of MPNST samples were assessed using TITAN (65) for pre, post, and recurrent samples compared to blood exome. Default ploidy values were set to two and converge parameters were set to default values. Segment calls generated by TITAN were used for both genome wide and inferred gene specific copy number alternation analyses.

\section{Development of NF1-MET, NF1-P53, and NF1 mice}

$\mathrm{NF}^{\mathrm{fl} / \mathrm{KO}} ;$;ox-stop-loxMET ${ }^{\mathrm{tg} /+} ; \mathrm{Plp}-\mathrm{CreERT}^{\mathrm{tg} /+}$ mice and controls were created to examine the combination of conditional NF1 loss of heterozygosity $(42,43)$ with overexpression of a humanized MET transgene $(33,34)$. These two genetic events were targeted to occur in myelinating cells immediately after birth using a tamoxifen-inducible Plp-creERT transgene (44) in mice with a global, constitutive mutation of the other allele of $N F 1 . N F 1^{f /+}$ mice were obtained from the $\mathrm{NCl}$ Frederick repository. $N F 1^{K O /+}$ mice were created by breeding $N F 1^{f / /+}$ mice to $C M V$-Cre mice (66). 
Only second generation or later $N F 1^{K O /+}$; Cre-negative animals were used for subsequent breeding. Plp-creERT (B6.Cg-Tg(Plp1-cre/ERT)3Pop/J ) and CMV-Cre(BALB/c-Tg(CMVcre)1Cgn/J) transgenic mice were obtained from The Jackson Laboratory. NF1 ${ }^{f / K O}$;lox-stop-

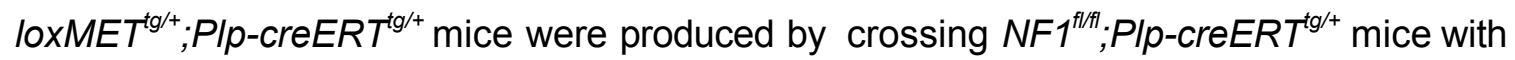
$N F 1^{K O /+} ;$ lox-stop-loxME $T^{t g /+}$ mice. Lactating dams were dosed with $100 \mu$ l of $20 \mathrm{mg} / \mathrm{ml}$ tamoxifen (Sigma) in corn oil (Acros Organics) by oral gavage b.i.d. on postnatal days 1-5, based on similar previous studies (31). Of note, crosses using $N F 1^{\text {fl/fl}} ; P / p$-creER $R T^{\text {tg/tg }}$ mice did not yield pups at expected Mendelian ratios and were not used for this study. $\mathrm{Nf}^{\mathrm{KO} /+}$ mice were created by breeding $N F 1^{f / /}$ mice to mice carrying a CMV-Cre transgene. Only second generation or later $N F 1^{K O /+}$; Crenegative animals were used for subsequent breeding. $N F 1^{K O /+} ; T P 53^{K O /+}$ mice were created by breeding $N F 1^{K O /+}$ mice to $129 S 4-T r p 53^{\text {tm2Tyj} / N c i ~ m i c e ~(f u n c t i o n a l l y ~} T P 53^{K O /+}$ ) (38). All $N F 1^{K O /+} ; T P 53^{K O /+}$ mice produced were bred to wildtype animals to confirm cis-conformation of $N F 1$ and TP53 as performed in Vogel et al. (67). Mice producing at $N F 1^{K O /+} ; T P 53^{K O /+}$ offspring when bred to wild-types were used as founders. All animal experimentation in this study was approved by the Van Andel Institute's Internal Animal Care and Use Committee. Details on mouse genotyping procedures are in Supplementary Data.

\section{Development of murine MPNST tumorgrafts and drug treatment}

Immediately following euthanasia of tumor bearing mice, $15-25 \mathrm{mg}$ portions of each tumor were transplanted into the flank of athymic nude mice using a 10 gauge trochar. Mice were examined weekly and euthanized when the tumor size exceeded $1500 \mathrm{~mm}^{3}$. For treatment studies, bulk tumor pieces were transplanted subcutaneously into athymic nude female mice and tumor growth was evaluated twice weekly. When tumor volume reached approximately $150 \mathrm{~mm}^{3}$, mice were randomized into vehicle, capmatinib $3 \mathrm{mg} / \mathrm{kg}, 10 \mathrm{mg} / \mathrm{kg}$, or $30 \mathrm{mg} / \mathrm{kg}$ treatment groups and dosed 5 days per week via oral gavage for 3 weeks or until mice reached euthanasia criteria. Capmatinib was obtained from Novartis. The tumors were measured twice weekly using a caliper and the 
tumor volumes were calculated as length $\mathrm{x}$ width $\mathrm{x}$ depth.

\section{Statistical Methods}

Kaplan-Meier curves were used to display tumor-free survival and, after verifying the proportional hazards assumption, Cox regression with false discovery rate adjusted contrasts were used to test for differences in tumor incidence rates between mouse lines. Three mice euthanized due to hindlimb paralysis had evidence of small paraspinal neoplasms at necropsy and were therefore included as tumor events. Genotypes with no tumor events are not shown. Logistic regression with false discovery rate adjusted contrasts were used to test for differences in the frequencies at which the different mouse lines were euthanized/died early due to tumor burden. Linear mixedeffects models with false discovery rate adjusted contrasts were used to estimate and compare tumor growth rates between different capmatinib dosages within each line. Fiellers's theorem with Bonferroni adjusted significance level was used to estimate the confidence intervals for the percent reduction in tumor growth rates for mice treated with capmatinib versus vehicle across the different lines (68). All analyses were conducted using R v3.2.2 (https://cran.r-project.org/) with an assumed level of significance of $\alpha=0.05$.

\section{Study Approval}

Tissue samples were collected in accordance with established IRB approved protocols at both Spectrum Health and the Van Andel Institute. Written informed consent was obtained from study participants prior to inclusion in the study.

Detailed Methods for genotyping, FISH analysis, histology, and western analysis can be found in the Supplemental Data. 


\section{Authors' Contributions}

Conception and design: JD Peacock, CR Graveel, MR Steensma

Development of methodology: JD Peacock, EA Tovar

Acquisition of data: JD Peacock, MG Pridgeon, EA Tovar, J Koeman, J Grit, CJ Essenburg

Analysis and interpretation of data: M Bowman, Z Madaj, RD Dodd, DM Cardona, M Chen,

DG Kirsch

Writing, review, and/or revision of the manuscript: JD Peacock, CR Graveel, MR Steensma

Administrative, technical, or material support: F Maina, R Dono

Study supervision: MR Steensma

\section{Grant Support}

Funding for this research was made possible by the Neurofibromatosis Therapeutic Acceleration Program (NTAP), The Johns Hopkins University (JHU), and the Van Andel Institute. Its contents are solely the responsibility of the authors and do not necessarily represent the official views of NTAP and JHU.

\section{Acknowledgements}

We would like to thank the MSU RTSF Genomics Core for genomic analysis of the MPNST models, Patrick Dischinger for technical assistance with this study, Amanda Schuiling for assistance with statistical analysis, and Anderson Peck from the VARI Small Animal Imaging Facility for his imaging support. We would like to thank Bryn Eagleson and the VARI Vivarium for their continuous dedication.

\section{Conflict of interest}

The authors have declared that no conflict of interest exists. 


\section{References}

1. Lammert M, Friedman JM, Kluwe L, Mautner VF. Prevalence of neurofibromatosis 1 in German children at elementary school enrollment. Arch Dermatol 2005;141(1):71-4.

2. Evans DG, Howard E, Giblin C, Clancy T, Spencer H, Huson SM, et al. Birth incidence and prevalence of tumor-prone syndromes: estimates from a UK family genetic register service. Am J Med Genet A 2010;152A(2):327-32.

3. Wallace MR, Marchuk DA, Andersen LB, Letcher R, Odeh HM, Saulino AM, et al. Type 1 neurofibromatosis gene: identification of a large transcript disrupted in three NF1 patients. Science 1990;249(4965):181-6.

4. Friedrich RE, Hartmann M, Mautner VF. Malignant peripheral nerve sheath tumors (MPNST) in NF1-affected children. Anticancer Res 2007;27(4A):1957-60.

5. Ingham S, Huson SM, Moran A, Wylie J, Leahy M, Evans DG. Malignant peripheral nerve sheath tumours in NF1: improved survival in women and in recent years. Eur J Cancer 2011;47(18):2723-8.

6. Evans DG, Baser ME, McGaughran J, Sharif S, Howard E, Moran A. Malignant peripheral nerve sheath tumours in neurofibromatosis 1. J Med Genet 2002;39(5):311-4.

7. Porter DE, Prasad V, Foster L, Dall GF, Birch R, Grimer RJ. Survival in Malignant Peripheral Nerve Sheath Tumours: A Comparison between Sporadic and Neurofibromatosis Type 1-Associated Tumours. Sarcoma 2009;2009:756395.

8. Watson KL, Al Sannaa GA, Kivlin CM, Ingram DR, Landers SM, Roland CL, et al. Patterns of recurrence and survival in sporadic, neurofibromatosis Type 1-associated, and radiation-associated malignant peripheral nerve sheath tumors. J Neurosurg 2017;126(1):319-29.

9. Peacock JD, Cherba D, Kampfschulte K, Smith MK, Monks NR, Webb CP, et al. Molecular-guided therapy predictions reveal drug resistance phenotypes and treatment alternatives in malignant peripheral nerve sheath tumors. J Transl Med 2013;11:213.

10. Brossier NM, Carroll SL. Genetically engineered mouse models shed new light on the pathogenesis of neurofibromatosis type I-related neoplasms of the peripheral nervous system. Brain Res Bull 2012;88(1):58-71.

11. Park HJ, Lee SJ, Sohn YB, Jin HS, Han JH, Kim YB, et al. NF1 deficiency causes Bcl-xL upregulation in Schwann cells derived from neurofibromatosis type 1-associated malignant peripheral nerve sheath tumors. Int J Oncol 2013;42(2):657-66.

12. Patel AV, Eaves D, Jessen WJ, Rizvi TA, Ecsedy JA, Qian MG, et al. Ras-driven transcriptome analysis identifies aurora kinase $A$ as a potential malignant peripheral nerve sheath tumor therapeutic target. Clin Cancer Res 2012;18(18):5020-30.

13. Deadwyler GD, Dang I, Nelson J, Srikanth M, De Vries GH. Prostaglandin E(2) metabolism is activated in Schwann cell lines derived from human NF1 malignant peripheral nerve sheath tumors. Neuron Glia Biol 2004;1(2):149-55.

14. Joseph NM, Mosher JT, Buchstaller J, Snider P, McKeever PE, Lim M, et al. The loss of $\mathrm{Nf1}$ transiently promotes self-renewal but not tumorigenesis by neural crest stem cells. Cancer Cell 2008;13(2):129-40.

15. Perrin GQ, Fishbein L, Thomson SA, Thomas SL, Stephens K, Garbern JY, et al. Plexiform-like neurofibromas develop in the mouse by intraneural xenograft of an NF1 
tumor-derived Schwann cell line. J Neurosci Res 2007;85(6):1347-57.

16. Varin J, Poulain L, Hivelin M, Nusbaum P, Hubas A, Laurendeau I, et al. Dual mTORC1/2 inhibition induces anti-proliferative effect in NF1-associated plexiform neurofibroma and malignant peripheral nerve sheath tumor cells. Oncotarget 2016;7(24):35753-67.

17. Masliah-Planchon J, Pasmant E, Luscan A, Laurendeau I, Ortonne N, Hivelin M, et al. MicroRNAome profiling in benign and malignant neurofibromatosis type 1-associated nerve sheath tumors: evidences of PTEN pathway alterations in early NF1 tumorigenesis. BMC Genomics 2013;14:473.

18. Le LQ, Parada LF. Tumor microenvironment and neurofibromatosis type I: connecting the GAPs. Oncogene 2007;26(32):4609-16.

19. Cichowski K, Shih TS, Schmitt E, Santiago S, Reilly K, McLaughlin ME, et al. Mouse models of tumor development in neurofibromatosis type 1. Science 1999;286(5447):21726.

20. Kourea HP, Cordon-Cardo C, Dudas M, Leung D, Woodruff JM. Expression of p27(kip) and other cell cycle regulators in malignant peripheral nerve sheath tumors and neurofibromas: the emerging role of p27(kip) in malignant transformation of neurofibromas. Am J Pathol 1999;155(6):1885-91.

21. Zhang $M$, Wang $Y$, Jones $S$, Sausen $M$, McMahon $K$, Sharma R, et al. Somatic mutations of SUZ12 in malignant peripheral nerve sheath tumors. Nat Genet 2014;46(11):1170-2.

22. Upadhyaya M, Spurlock G, Majounie E, Griffiths S, Forrester N, Baser M, et al. The heterogeneous nature of germline mutations in NF1 patients with malignant peripheral serve sheath tumours (MPNSTs). Hum Mutat 2006;27(7):716.

23. Miller SJ, Rangwala F, Williams J, Ackerman P, Kong S, Jegga AG, et al. Large-scale molecular comparison of human schwann cells to malignant peripheral nerve sheath tumor cell lines and tissues. Cancer Res 2006;66(5):2584-91.

24. Mantripragada KK, Spurlock G, Kluwe L, Chuzhanova N, Ferner RE, Frayling IM, et al. High-resolution DNA copy number profiling of malignant peripheral nerve sheath tumors using targeted microarray-based comparative genomic hybridization. Clin Cancer Res 2008;14(4):1015-24.

25. Gherardi E, Birchmeier W, Birchmeier C, Vande Woude G. Targeting MET in cancer: rationale and progress. Nat Rev Cancer 2012;12(2):89-103.

26. Trusolino L, Bertotti A, Comoglio PM. MET signalling: principles and functions in development, organ regeneration and cancer. Nat Rev Mol Cell Biol 2010;11(12):834-48.

27. Peters S, Adjei AA. MET: a promising anticancer therapeutic target. Nat Rev Clin Oncol 2012;9(6):314-26.

28. Rao UN, Sonmez-Alpan E, Michalopoulos GK. Hepatocyte growth factor and c-MET in benign and malignant peripheral nerve sheath tumors. Hum Pathol 1997;28(9):1066-70.

29. Torres KE, Zhu QS, Bill K, Lopez G, Ghadimi MP, Xie X, et al. Activated MET is a molecular prognosticator and potential therapeutic target for malignant peripheral nerve sheath tumors. Clin Cancer Res 2011;17(12):3943-55.

30. Mayes DA, Rizvi TA, Cancelas JA, Kolasinski NT, Ciraolo GM, Stemmer-Rachamimov $\mathrm{AO}$, et al. Perinatal or adult Nf1 inactivation using tamoxifen-inducible PlpCre each cause neurofibroma formation. Cancer Res 2011;71(13):4675-85. 
31. Le LQ, Liu C, Shipman T, Chen Z, Suter U, Parada LF. Susceptible stages in Schwann cells for NF1-associated plexiform neurofibroma development. Cancer Res 2011;71(13):4686-95.

32. Dodd RD, Mito JK, Eward WC, Chitalia R, Sachdeva M, Ma Y, et al. NF1 deletion generates multiple subtypes of soft-tissue sarcoma that respond to MEK inhibition. Mol Cancer Ther 2013;12(9):1906-17.

33. Genestine M, Caricati E, Fico A, Richelme S, Hassani H, Sunyach C, et al. Enhanced neuronal Met signalling levels in ALS mice delay disease onset. Cell Death Dis 2011;2:e130.

34. Fan Y, Richelme S, Avazeri E, Audebert S, Helmbacher F, Dono R, et al. Tissue-Specific Gain of RTK Signalling Uncovers Selective Cell Vulnerability during Embryogenesis. PLoS Genet 2015;11(9):e1005533.

35. Zhu Y, Romero MI, Ghosh P, Ye Z, Charnay P, Rushing EJ, et al. Ablation of NF1 function in neurons induces abnormal development of cerebral cortex and reactive gliosis in the brain. Genes Dev 2001;15(7):859-76.

36. Leone DP, Genoud S, Atanasoski S, Grausenburger R, Berger P, Metzger D, et al. Tamoxifen-inducible glia-specific Cre mice for somatic mutagenesis in oligodendrocytes and Schwann cells. Mol Cell Neurosci 2003;22(4):430-40.

37. Stemmer-Rachamimov AO, Louis DN, Nielsen GP, Antonescu CR, Borowsky AD, Bronson $\mathrm{RT}$, et al. Comparative pathology of nerve sheath tumors in mouse models and humans. Cancer Res 2004;64(10):3718-24.

38. Olive KP, Tuveson DA, Ruhe ZC, Yin B, Willis NA, Bronson RT, et al. Mutant p53 gain of function in two mouse models of Li-Fraumeni syndrome. Cell 2004;119(6):847-60.

39. Maertens O, Johnson B, Hollstein P, Frederick DT, Cooper ZA, Messiaen L, et al. Elucidating distinct roles for NF1 in melanomagenesis. Cancer Discov 2013;3(3):338-49.

40. Ma B, Bang YJ, Lim WT, Nam DH, Su WC, Schellens JHM, et al. P1.04Phase I dose escalation and expansion study to evaluate safety and efficacy of INC280 in patients with advanced MET-dependent solid tumors. Annals of Oncology 2015;26(suppl_2):ii17-ii17.

41. Bang Y-J, Su W-C, Nam D-H, Lim W-T, Bauer TM, Brana I, et al. Phase I study of the safety and efficacy of INC280 in patients with advanced MET-dependent solid tumors. Journal of Clinical Oncology 2014;32(15_suppl):2520-20.

42. Liu X, Wang Q, Yang G, Marando C, Koblish HK, Hall LM, et al. A novel kinase inhibitor, INCB28060, blocks c-MET-dependent signaling, neoplastic activities, and cross-talk with EGFR and HER-3. Clin Cancer Res 2011;17(22):7127-38.

43. Spurlock G, Knight SJ, Thomas N, Kiehl TR, Guha A, Upadhyaya M. Molecular evolution of a neurofibroma to malignant peripheral nerve sheath tumor (MPNST) in an NF1 patient: correlation between histopathological, clinical and molecular findings. J Cancer Res Clin Oncol 2010;136(12):1869-80.

44. Castellsague J, Gel B, Fernandez-Rodriguez J, Llatjos R, Blanco I, Benavente Y, et al. Comprehensive establishment and characterization of orthoxenograft mouse models of malignant peripheral nerve sheath tumors for personalized medicine. EMBO Mol Med 2015;7(5):608-27.

45. Greenman C, Stephens P, Smith R, Dalgliesh GL, Hunter C, Bignell G, et al. Patterns of somatic mutation in human cancer genomes. Nature 2007;446(7132):153-8. 
46. Rahrmann EP, Watson AL, Keng VW, Choi K, Moriarity BS, Beckmann DA, et al. Forward genetic screen for malignant peripheral nerve sheath tumor formation identifies new genes and pathways driving tumorigenesis. Nat Genet 2013;45(7):756-66.

47. Hirbe AC, Dahiya S, Miller CA, Li T, Fulton RS, Zhang X, et al. Whole Exome Sequencing Reveals the Order of Genetic Changes during Malignant Transformation and Metastasis in a Single Patient with NF1-plexiform Neurofibroma. Clin Cancer Res 2015;21(18):4201-11.

48. Brekke HR, Kolberg M, Skotheim RI, Hall KS, Bjerkehagen B, Risberg B, et al. Identification of $\mathrm{p} 53$ as a strong predictor of survival for patients with malignant peripheral nerve sheath tumors. Neuro Oncol 2009;11(5):514-28.

49. Rahrmann EP, Moriarity BS, Otto GM, Watson AL, Choi K, Collins MH, et al. Trp53 haploinsufficiency modifies EGFR-driven peripheral nerve sheath tumorigenesis. Am J Pathol 2014;184(7):2082-98.

50. Cepero V, Sierra JR, Corso S, Ghiso E, Casorzo L, Perera T, et al. MET and KRAS gene amplification mediates acquired resistance to MET tyrosine kinase inhibitors. Cancer Res 2010;70(19):7580-90.

51. Kwak EL, Ahronian LG, Siravegna G, Mussolin B, Godfrey JT, Clark JW, et al. Molecular Heterogeneity and Receptor Coamplification Drive Resistance to Targeted Therapy in MET-Amplified Esophagogastric Cancer. Cancer Discov 2015;5(12):1271-81.

52. Fujita-Sato S, Galeas J, Truitt M, Pitt C, Urisman A, Bandyopadhyay S, et al. Enhanced MET Translation and Signaling Sustains K-Ras-Driven Proliferation under AnchorageIndependent Growth Conditions. Cancer Res 2015;75(14):2851-62.

53. Wilson TR, Fridlyand J, Yan Y, Penuel E, Burton L, Chan E, et al. Widespread potential for growth-factor-driven resistance to anticancer kinase inhibitors. Nature 2012;487(7408):505-9.

54. Chen CT, Kim H, Liska D, Gao S, Christensen JG, Weiser MR. MET activation mediates resistance to lapatinib inhibition of HER2-amplified gastric cancer cells. Mol Cancer Ther 2012;11(3):660-9.

55. Turke AB, Zejnullahu K, Wu YL, Song Y, Dias-Santagata D, Lifshits E, et al. Preexistence and clonal selection of MET amplification in EGFR mutant NSCLC. Cancer Cell 2010;17(1):77-88.

56. Paulson AK, Linklater ES, Berghuis BD, App CA, Oostendorp LD, Paulson JE, et al. MET and ERBB2 are coexpressed in ERBB2+ breast cancer and contribute to innate resistance. Mol Cancer Res 2013;11(9):1112-21.

57. Albritton KH, Rankin C, Coffin CM, Ratner N, Budd GT, Schuetze SM, et al. Phase II study of erlotinib in metastatic or unresectable malignant peripheral nerve sheath tumors (MPNST). Journal of Clinical Oncology 2006;24(18_suppl):9518-18.

58. Li H, Velasco-Miguel S, Vass WC, Parada LF, DeClue JE. Epidermal growth factor receptor signaling pathways are associated with tumorigenesis in the Nf1:p53 mouse tumor model. Cancer Res 2002;62(15):4507-13.

59. Corso S, Ghiso E, Cepero V, Sierra JR, Migliore C, Bertotti A, et al. Activation of HER family members in gastric carcinoma cells mediates resistance to MET inhibition. Mol Cancer 2010;9:121.

60. Pridgeon MG, Tovar EA, Essenburg CJ, Madaj Z, Boguslawski EA, Dischinger PS, et al. Oncogenic RAS-MET signal interactions are modulated by P53 status in NF1-related 
MPNSTs. Submitted 2017.

61. McKenna A, Hanna M, Banks E, Sivachenko A, Cibulskis K, Kernytsky A, et al. The Genome Analysis Toolkit: a MapReduce framework for analyzing next-generation DNA sequencing data. Genome Res 2010;20(9):1297-303.

62. DePristo MA, Banks E, Poplin R, Garimella KV, Maguire JR, Hartl C, et al. A framework for variation discovery and genotyping using next-generation DNA sequencing data. Nat Genet 2011;43(5):491-8.

63. Van der Auwera GA, Carneiro MO, Hartl C, Poplin R, Del Angel G, Levy-Moonshine A, et al. From FastQ data to high confidence variant calls: the Genome Analysis Toolkit best practices pipeline. Curr Protoc Bioinformatics 2013;43:11 10 1-33.

64. Cibulskis K, Lawrence MS, Carter SL, Sivachenko A, Jaffe D, Sougnez C, et al. Sensitive detection of somatic point mutations in impure and heterogeneous cancer samples. Nat Biotechnol 2013;31(3):213-9.

65. Ha G, Roth A, Khattra J, Ho J, Yap D, Prentice LM, et al. TITAN: inference of copy number architectures in clonal cell populations from tumor whole-genome sequence data. Genome Res 2014;24(11):1881-93.

66. Schwenk F, Baron U, Rajewsky K. A cre-transgenic mouse strain for the ubiquitous deletion of loxP-flanked gene segments including deletion in germ cells. Nucleic Acids Res 1995;23(24):5080-1.

67. Vogel KS, Klesse LJ, Velasco-Miguel S, Meyers K, Rushing EJ, Parada LF. Mouse tumor model for neurofibromatosis type 1. Science 1999;286(5447):2176-9.

68. Beyene J, Moineddin R. Methods for confidence interval estimation of a ratio parameter with application to location quotients. BMC Med Res Methodol 2005;5:32. 


\section{Figure Legends}

Figure 1: Comprehensive, longitudinal genomic analysis demonstrates targetable genetic changes early in disease progression. (A) Timeline with treatments (upper) and biopsy samples (arrows, lower; $n=1$ sample per time point) from an MPNST and associated plexiform neurofibroma in an adolescent male with Neurofibromatosis type 1. (B) The MPNST (indicated by blue dotted line) progression was imaged by magnetic resonance imaging at diagnosis (left panel) and post- treatment (middle panel). The recurrence was imaged by computerized axial tomography (CAT) (right panel). (C) Summary of genomic copy number changes across the four tumor samples. The plexiform neurofibroma (inner ring, a) was genomically normal. Increased copy number gains (orange), and deletions (green) throughout the progression of the pretreatment MPNST (ring b), post-treatment MPNST (ring c) and recurrent MPNST (ring d). (D) Detailed assessment of copy number changes in known MPNST-related genes with overlaid sequence alteration data identified allele-specific copy number amplifications (ASCNA), balanced copy number amplifications (BCNA), deletion LOH (DLOH), heterozygous alleles (HET), and copy-neutral LOH (NLOH) . Triangles indicate a non-synonymous coding change in TP53 (NC_000017.11:g.7673223G>C).

Figure 2: Gain of MET, HGF, EGFR and loss of NF1 and P53 copy number observed during MPNST progression. TITAN copy number analysis of variants found between blood and MPNST samples for each stage of progression was performed on A) Chromosome 7 and B) Chromosome 17. Blue $=$ Neutral, Green $=$ Hemizygous loss of heterozygosity, Red $=$ Gain.$(n=1$ sample per time point).

\section{Figure 3: Met activation drives malignant tumorigenesis in a mouse model of NF1-related}

MPNST. (A) Schematic of mouse genetics. Mice have a global loss of one NF1 allele, and they have a loss of the second copy of NF1 plus activation of a MET overexpressing transgene in 
myelinating cells following tamoxifen-induction of Plp1-Cre/ERT activity at postnatal day 1-5. (B) Allele-specific PCR for a mouse with the combined NF1 loss and MET overexpression genotype shows absence of an unaltered NF1 allele (Wildtype NF1) and presence of the functional but loxp flanked NF1 allele (NF1 flox); the recombined, loss-of-function NF1KO allele (NF1 recombined); the inactive lox-stop-loxMET transgene (MET tg/rec, lower band) and the recombined tgMET transgene (MET tg/rec, upper band); and the PIp1-Cre/ERT transgene(PIp1-Cre). The first lane contains a DNA ladder. (C) Tumor-free interval data for all models plotted as Kaplan-Meier curves. NF1fI/KO;MET;Cre mice developed tumors significantly sooner than all other mouse lines (indicated by *). (D) Cause of death in the 600 day observation period is plotted by frequency. Blue indicates death or euthanasia related to tumor burden, greys indicate healthy after 600 days or death due to other causes. E) H\&E staining confirmed MPNST histology (representative images shown of 6 samples assessed in triplicate). Ki67 verified high rates of proliferation. High pERK and pS6 were observed by immunohistochemistry, however high MET activation (pMET) was only present in the NF1- MET MPNST.

Figure 4: Interphase FISH demonstrates copy number gain of Met and Hgf in NF1-MET, NF1-P53, and NF1 MPNSTs. (A) No changes in endogenous Met (orange signal) and Hgf (red) copy number are observed in an MPNST from a NF1-MET mouse (MET transgene presence was confirmed, see Supplemental Figure 1). (B) Gain in endogenous Hgf copy number is observed in $12.5 \%$ of cells in a NF1 MPNST. (C) Gains in endogenous Met copy number is observed in an NF1-P53 MPNST with 4 copies in $49.5 \%$ of cells, 3 copies in $4 \%$ of cells, 6 copies in $5 \%$ of cells. An additional $6 \%$ of cells appear tetraploid with 8 copies of Met and 4 copies of Hgf. DAPI counterstain is shown in blue. Sample sizes and experimental details in Supplemental Table 3.

\section{Figure 5: Response to MET inhibition of NF1-MET, NF1-P53, and NF1 MPNSTs. MET} activation (pMET 1234/1235) and pERK1/2 (T202/Y204) areas inhibited by 5 nM INC280 in NF1- 
MET MPNSTs. ERK signaling was unaffected by INC280 treatment in NF1-P53 and NF1 tumors. Cells were serum starved overnight, then treated with INC280 for 2 hours. HGF $(100 \mathrm{ng} / \mathrm{mL})$ was added for 15 minutes before harvesting lysates. Representative images shown for 3 samples assessed (westerns were repeated in triplicate).

Figure 6: Tumorgrafts are differentially sensitive to MET inhibition with capmatinib. (A) Individual tumor growth plotted by line and treatment over 20 days. (B) Spline interpolated means and standard errors are plotted at each timepoint ( $\mathrm{N}=8$ mice per group). Curves terminate once $>70 \%$ of mice have been euthanized in the respective treatment group. (C) Mean percent reduction in growth rates of mice treated with $30 \mathrm{mg} / \mathrm{kg}$ of capmatinib versus vehicle. Error bars are $95 \%$, Bonferroni adjusted false coverage intervals, estimated via Fieller's theorem. (D) An * indicates non-overlapping confidence intervals between the three treatment groups. (E) Estimated mean differences between all treatments with $95 \%$ false coverage intervals by comparison and PDX line. Intervals are plotted on the same scale to highlight the differential tumor growth rates.

\section{Supplemental Tables and Figures Legends:}

Supplemental Table 1: Cox Regression Analysis of Tumor-Free Survival. Results from testing for differences in tumor-free survival times between mouse lines. Mouse line $N F 1^{f / K O} ; M E T ; C r e$ was used as the reference group. FDR $q$ represents false discovery rate adjusted $p$-values.

Supplemental Table 2: Logistic Regression Analysis of Cause of Death Frequency. Results from testing for differences in the proportion of mice that had deaths related to tumor burden. FDR $q$ represents false discovery rate adjusted $p$-values. 
Supplemental Table 3: Summary of R26-MET transgene localization. Interphase FISH analysis spleen and MPNST cells from NF1-MET mice was performed and the r26-MET (green) signal was assessed. Note that several tumors had diploid and tetraploid cells present.

\section{Supplemental Table 4: Copy number analysis of Met and Hgf in murine MPNST models.}

Relative copy number of Met and HGF was measured using dual-color interphase FISH on tumor touch preps from NF1-MET, NF1-P53, and NF1 MPNSTs. A summary of the FISH signals for the 6A2-1 and 6A2-2 (mouse Met) orange, and 5A2-2 (mouse Hgf) red is shown.

\section{Supplementary Table 5: Linear Mixed-Effects Modeling of Tumorgraft Results.}

Results of linear mixed-effects models, by line, which were used to estimate and identify differences in tumor growth rates. FDR $q$ is the false-discovery rate $q$ value (i.e. adjusted $p$-value). $\mathrm{FCl}$ stands for false coverage interval and is the false-discovery rate adjusted analog to a confidence interval.

\section{Supplementary Table 6: Percent Reduction in Tumor Growth and Fieller Estimated}

Confidence Interval. Estimated percent reduction in growth rate, calculated as the mean growth rate of capmatinib $30 \mathrm{mg} / \mathrm{kg}$ normalized to the mean vehicle growth rate, by line. Fieller's theorem was used to calculate $95 \%$ confidence bounds, with Bonferroni adjustments for multiple testing.

\section{Supplemental Figure 1: Increase in MET copy number during MPNST progression.} Copy number changes in MET were confirmed with quantitative polymerase chain reaction using two assays. Average copy number is reported relative to blood DNA (N=2). Error bars indicate the standard error from technical triplicates.

Supplementary Figure 2: Metaphase FISH analysis of R26-MET transgene. FISH probes r26- 
bioRxiv preprint doi: https://doi.org/10.1101/199000; this version posted October 5, 2017. The copyright holder for this preprint (which was not certified by peer review) is the author/funder. All rights reserved. No reuse allowed without permission.

MET plasmid green, 6A2-1 (mouse Met) orange, and 5A2-2 (mouse HGF) red were used on normal spleen and MPNSTs from NF1-MET mice. 
bioRxiv preprint doi: https://doi.org/10.1101/199000; this version posted October 5, 2017. The copyright holder for this preprint (which was not

Figure 1 certified by peer review) is the author/funder. All rights reserved. No reuse allowed without permission.
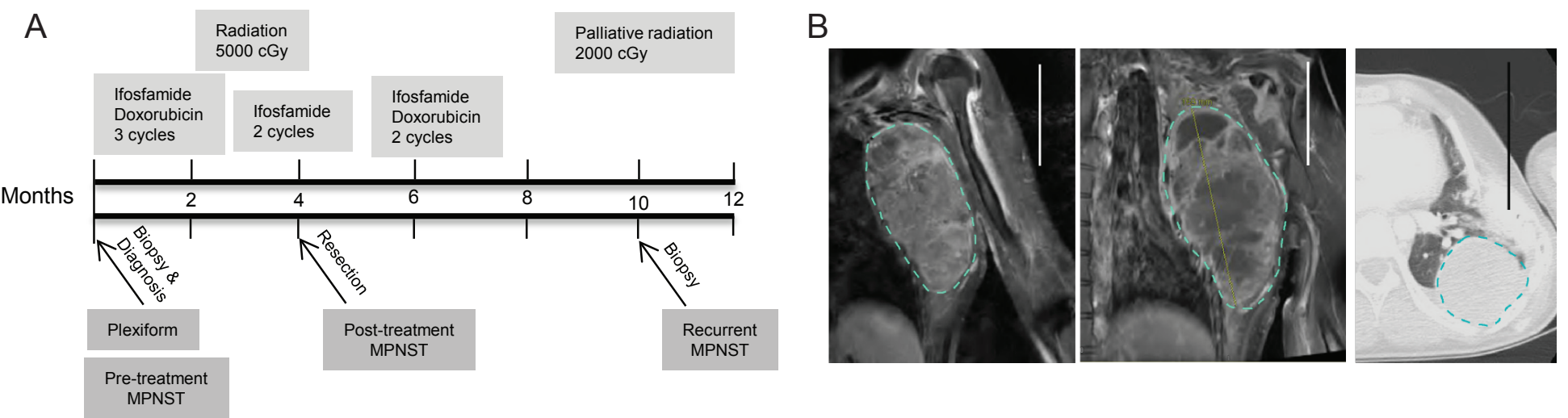

C
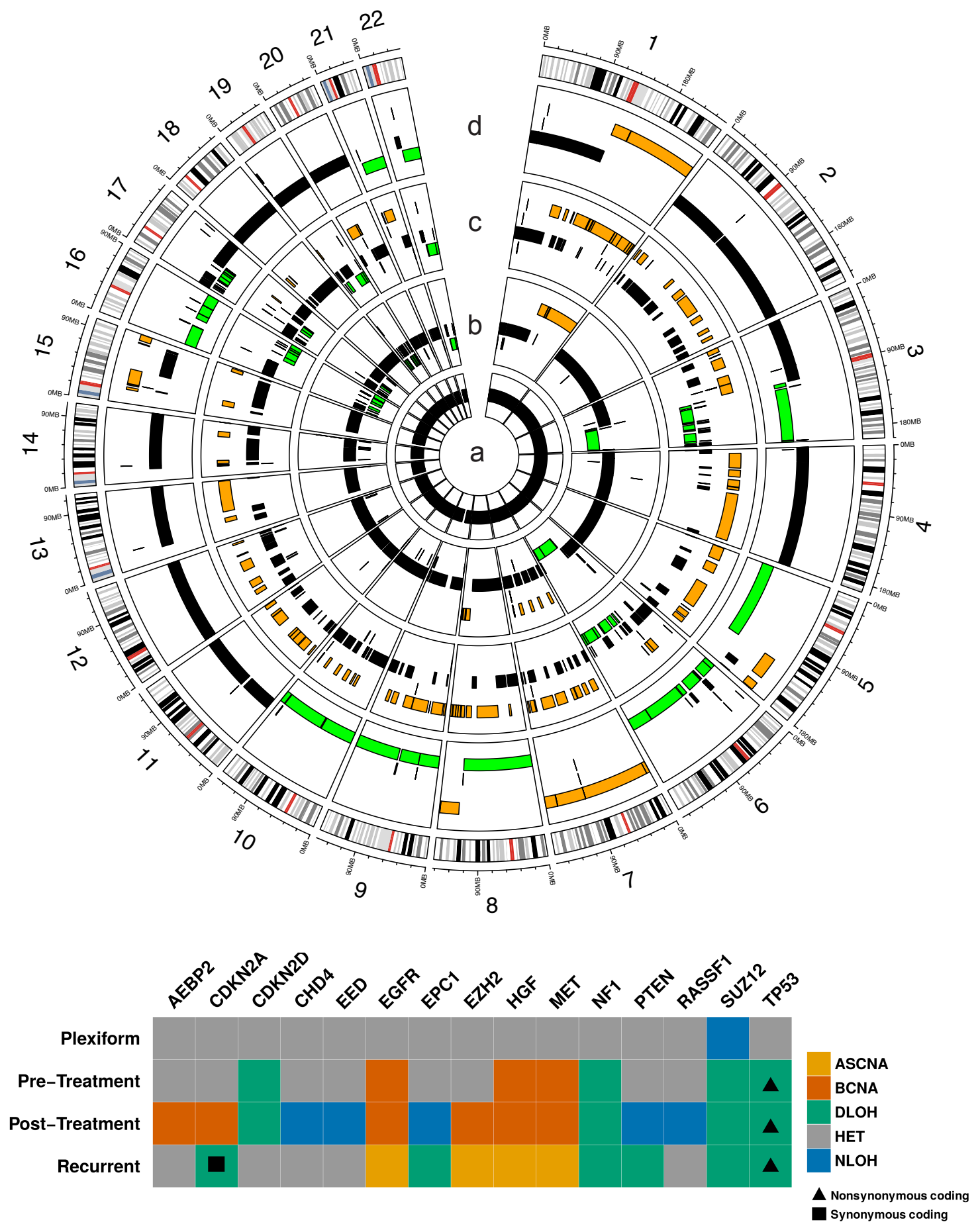
bioRxiv preprint doi: https://doi.org/10.1101/199000; this version posted October 5, 2017. The copyright holder for this preprint (which was not certified by peer review) is the author/funder. All rights reserved. No reuse allowed without permission.

Figure 2
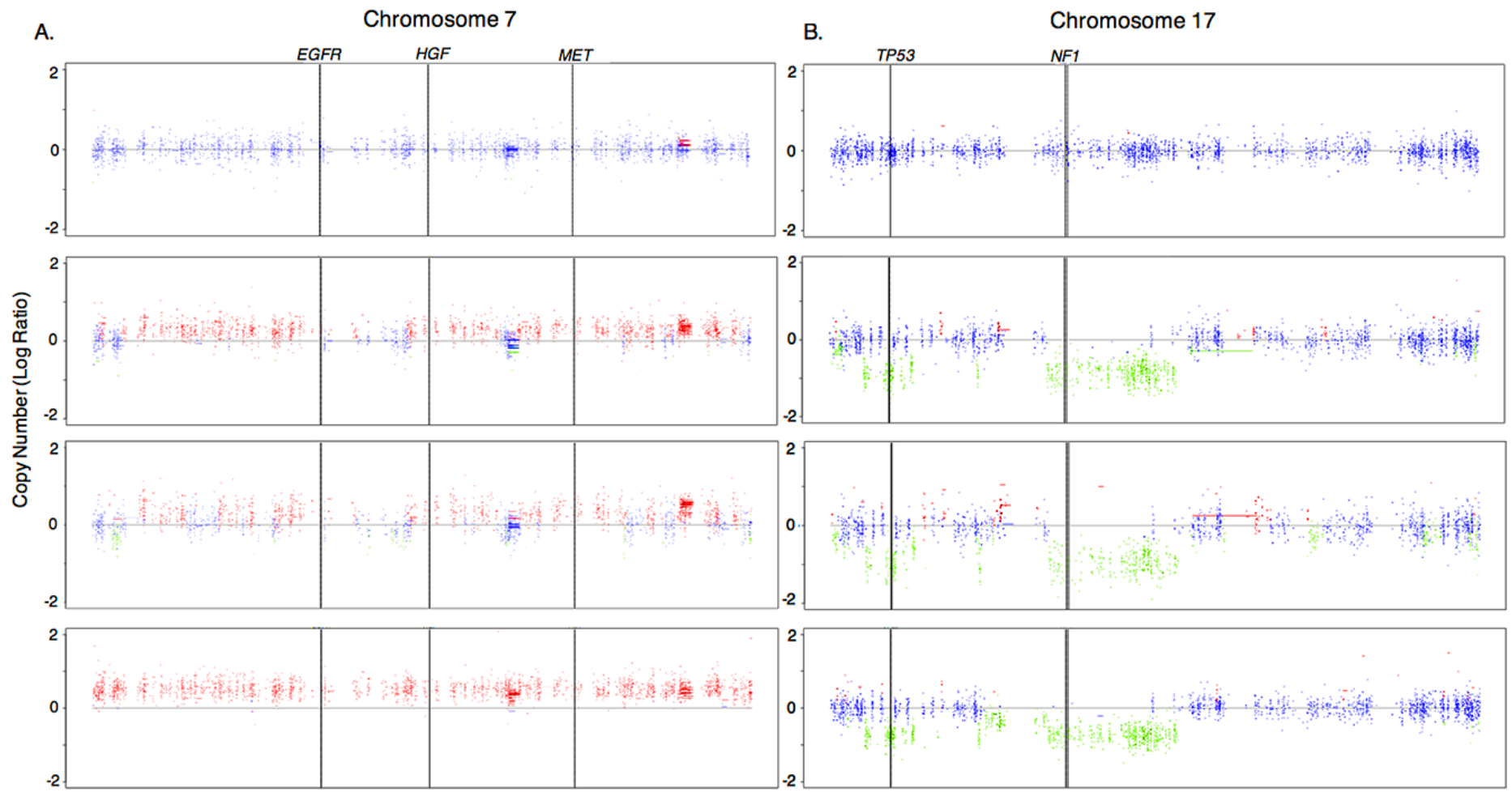
bioRxiv preprint doi: https://doi.org/10.1101/199000; this version posted October 5, 2017. The copyright holder for this preprint (which was not certified by peer review) is the author/funder. All rights reserved. No reuse allowed without permission.

Figure 3

A

$$
\begin{aligned}
& \text { NF1 } 1^{\text {fI/KO }} \text {;lox-stop-loxMET } T^{\mathrm{tg} /+} \text {; } \\
& \quad \text { PIp1-CRE/ERT }
\end{aligned}
$$

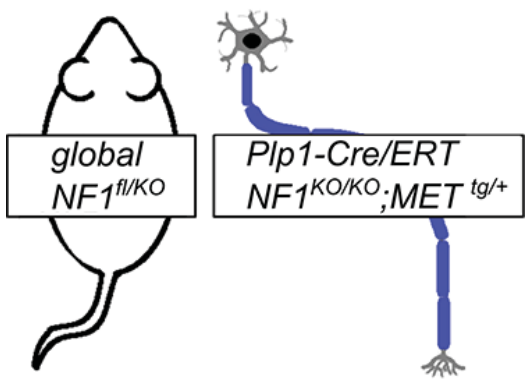

C

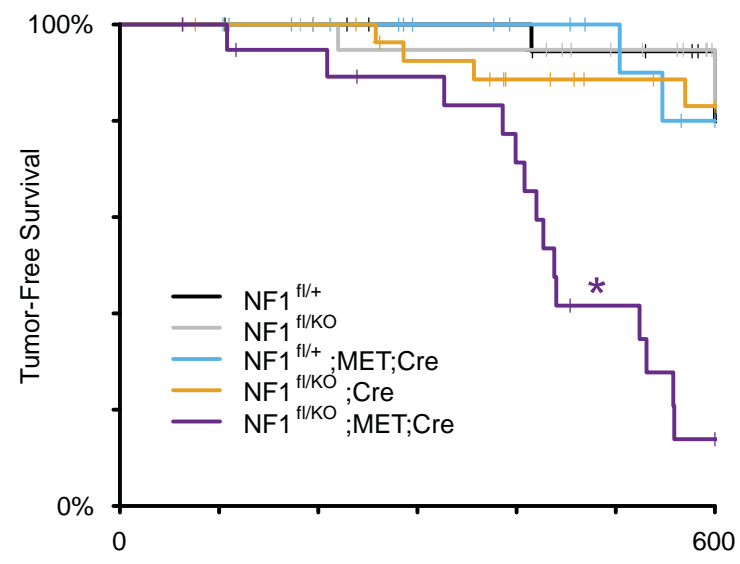

Days
B

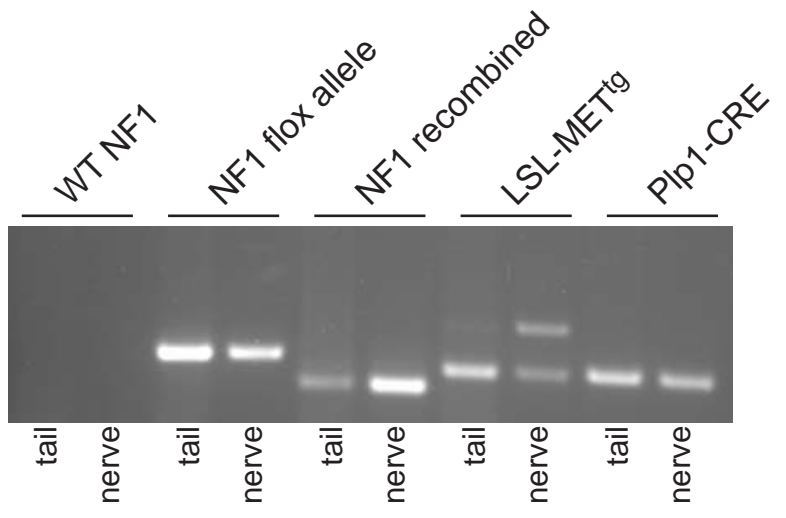

D

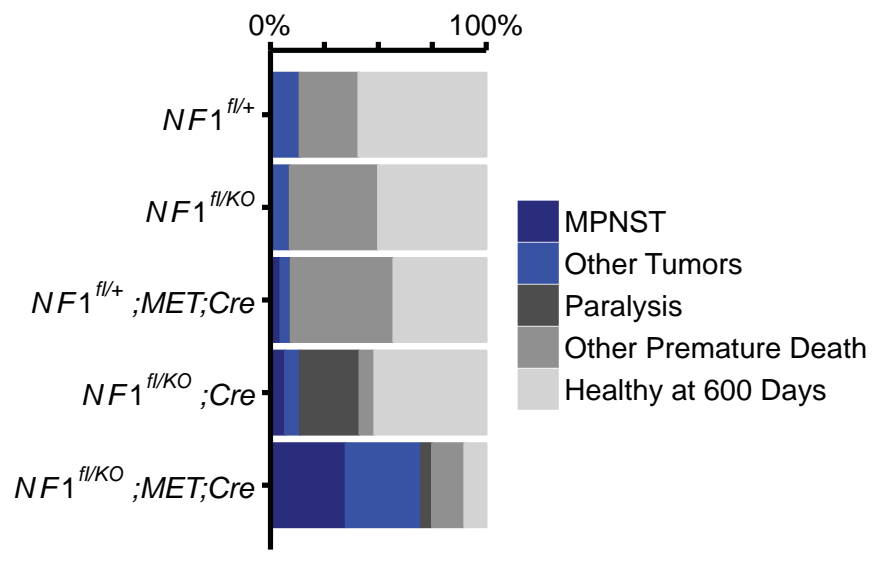

$E$

$H \& E$

Ki67

pMET

pERK

pS6
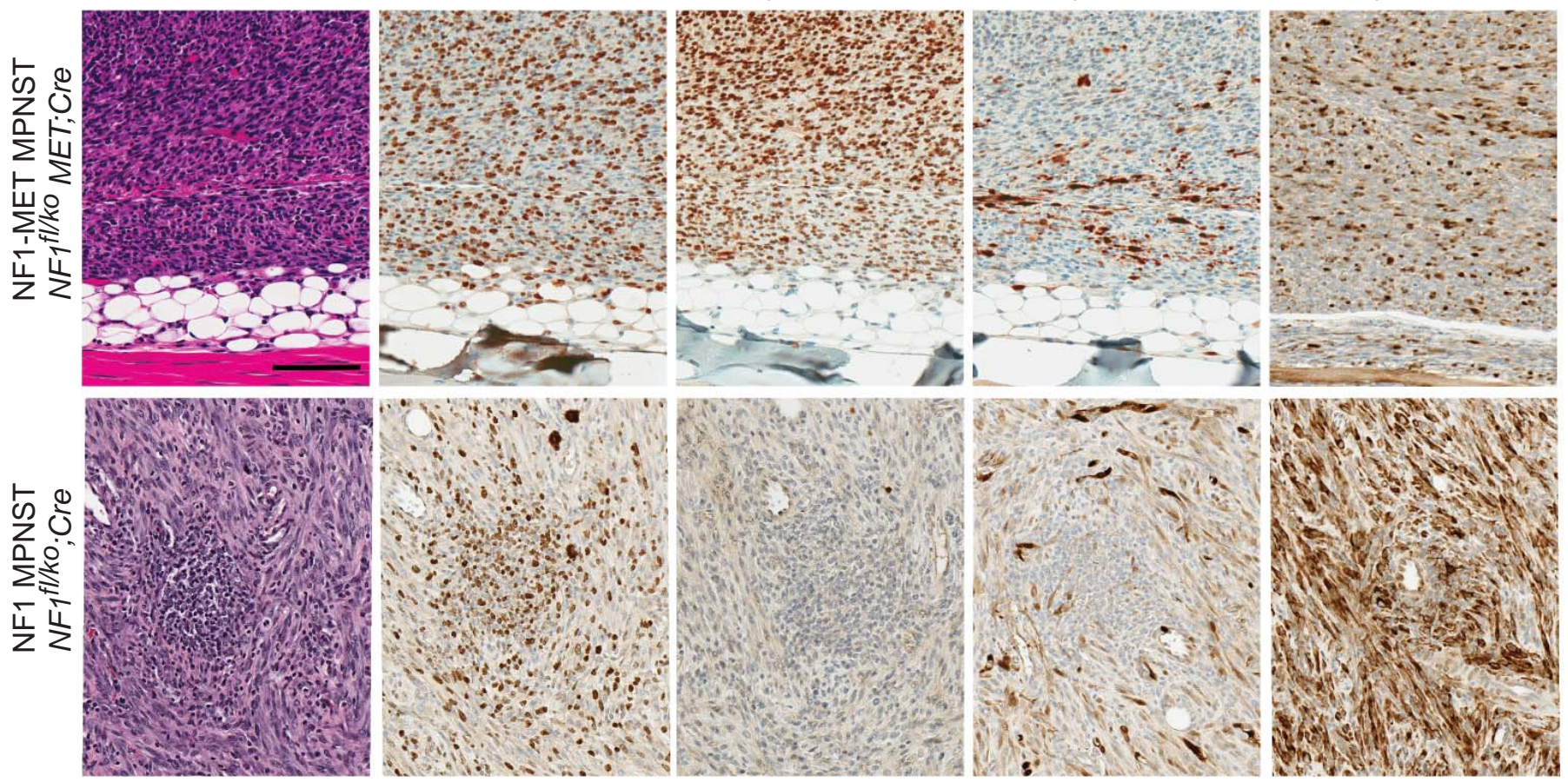
bioRxiv preprint doi: https://doi.org/10.1101/199000; this version posted October 5, 2017. The copyright holder for this preprint (which was not certified by peer review) is the author/funder. All rights reserved. No reuse allowed without permission.

Figure 4

A

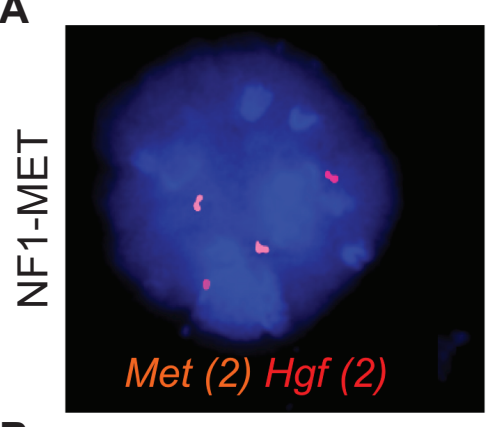

B

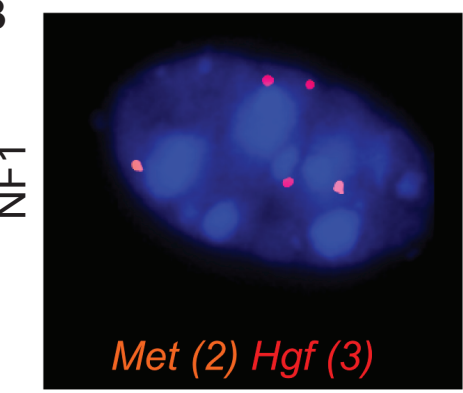

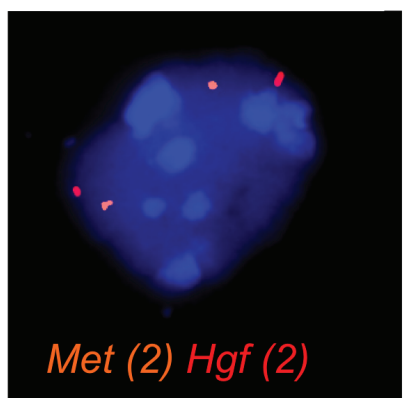

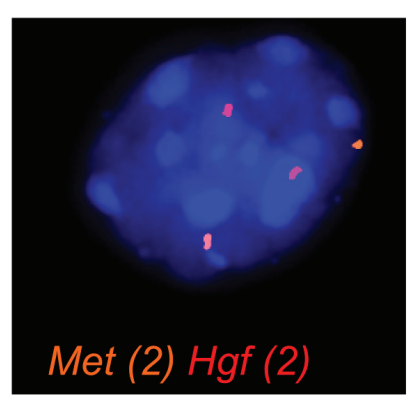

C
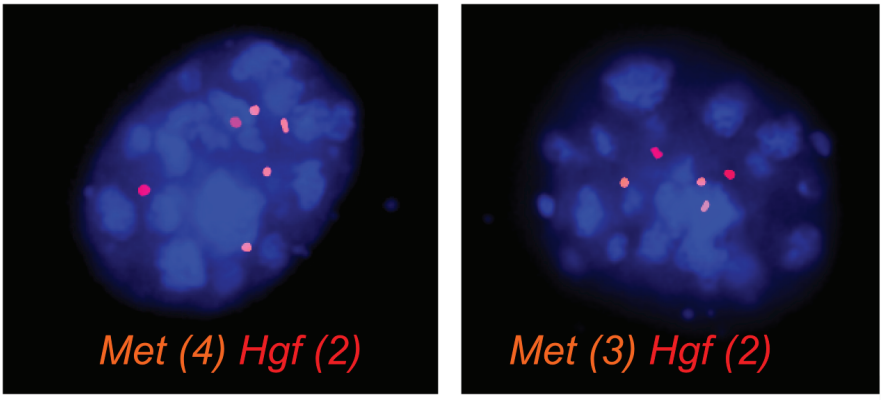

穵

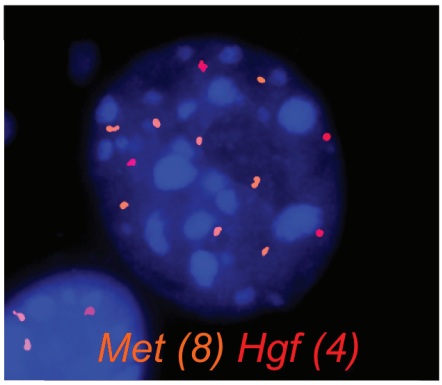




\section{Figure 5} certified by peer review) is the author/funder. All rights reserved. No reuse allowed without permission.

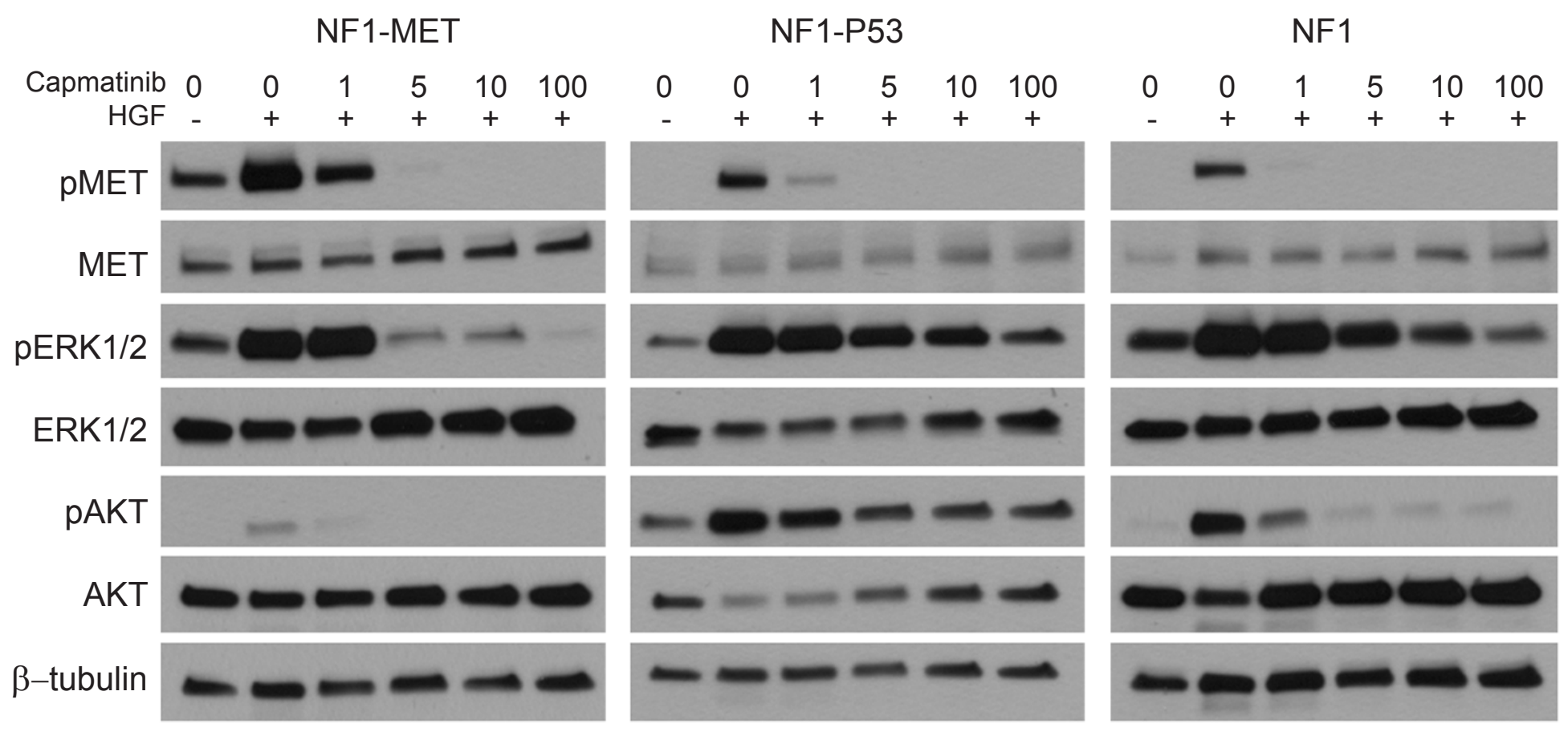




\section{Figure 6}

A
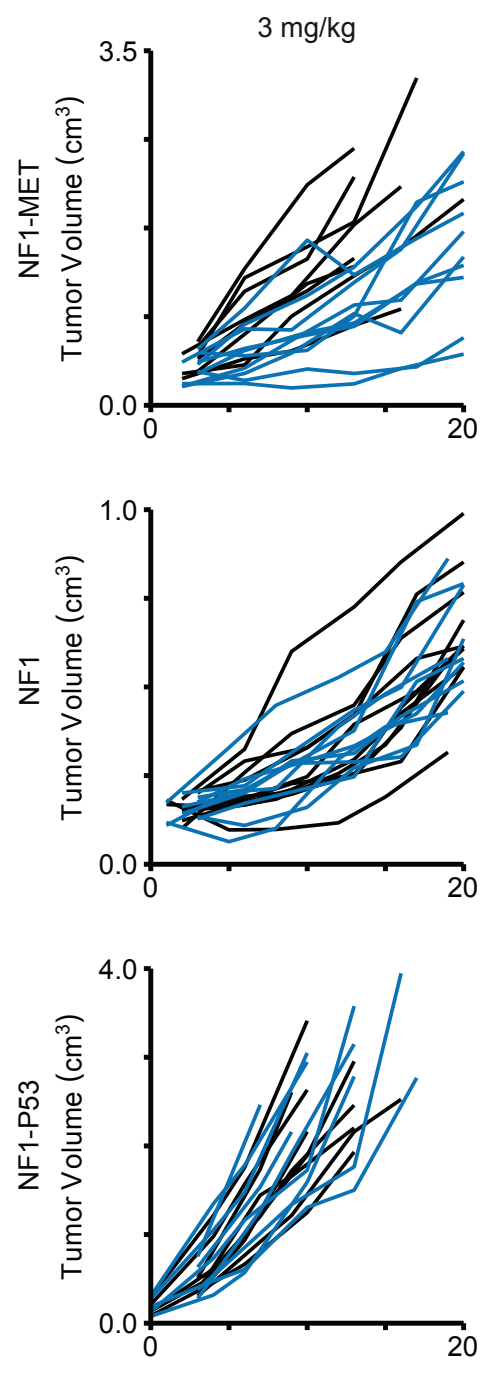

C

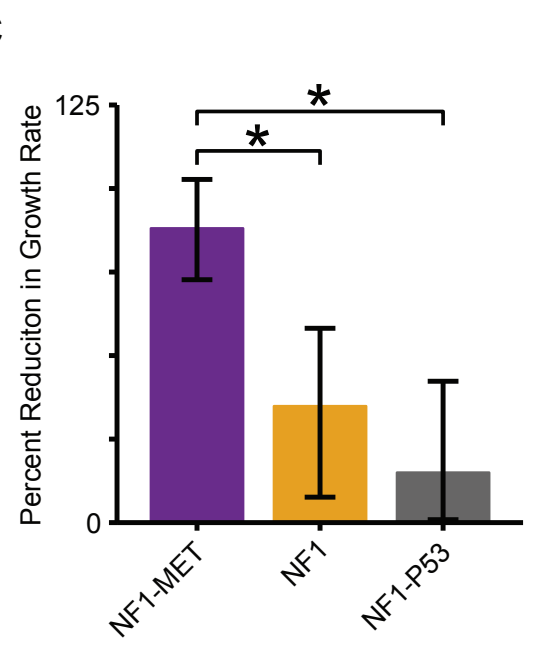

\section{Capmatinib}
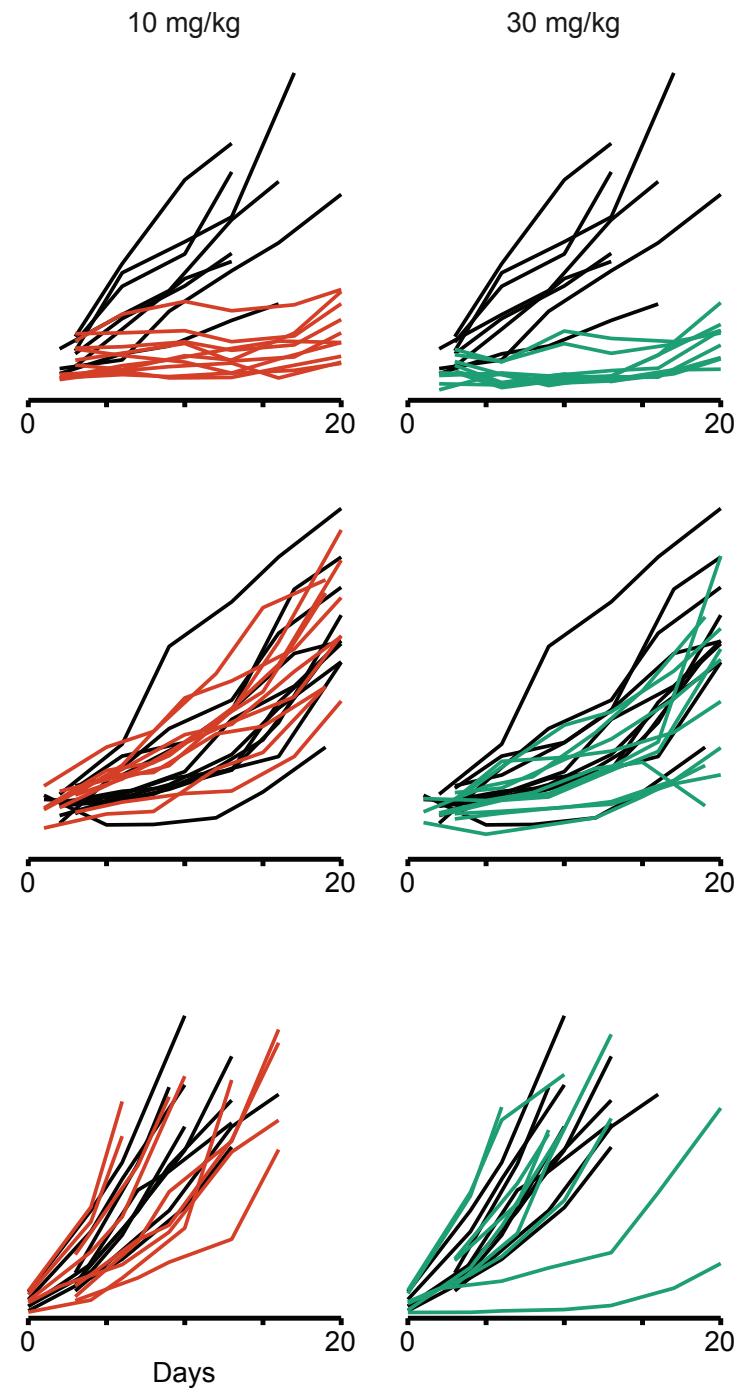

B
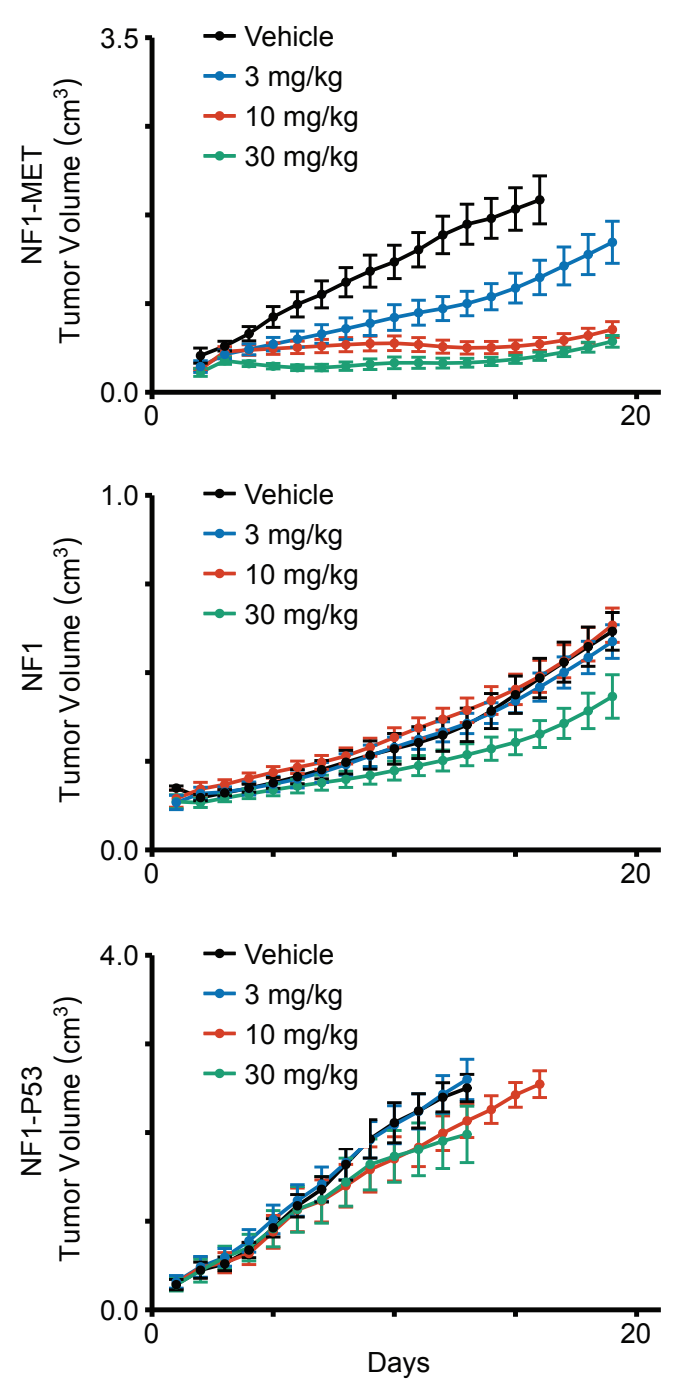

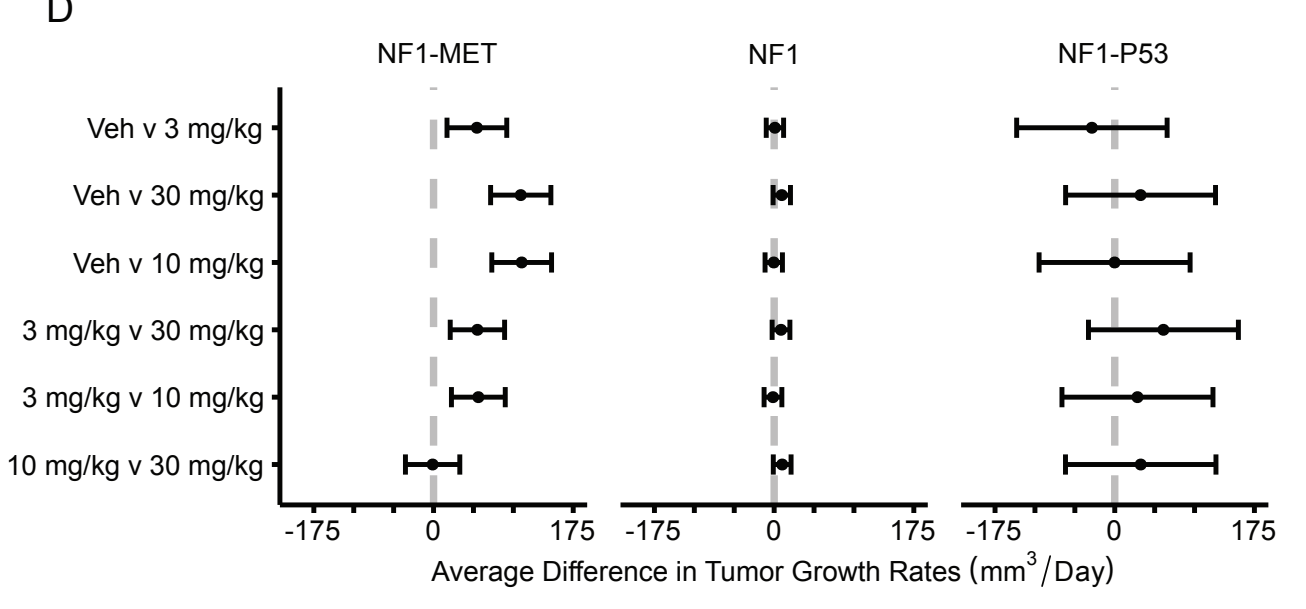




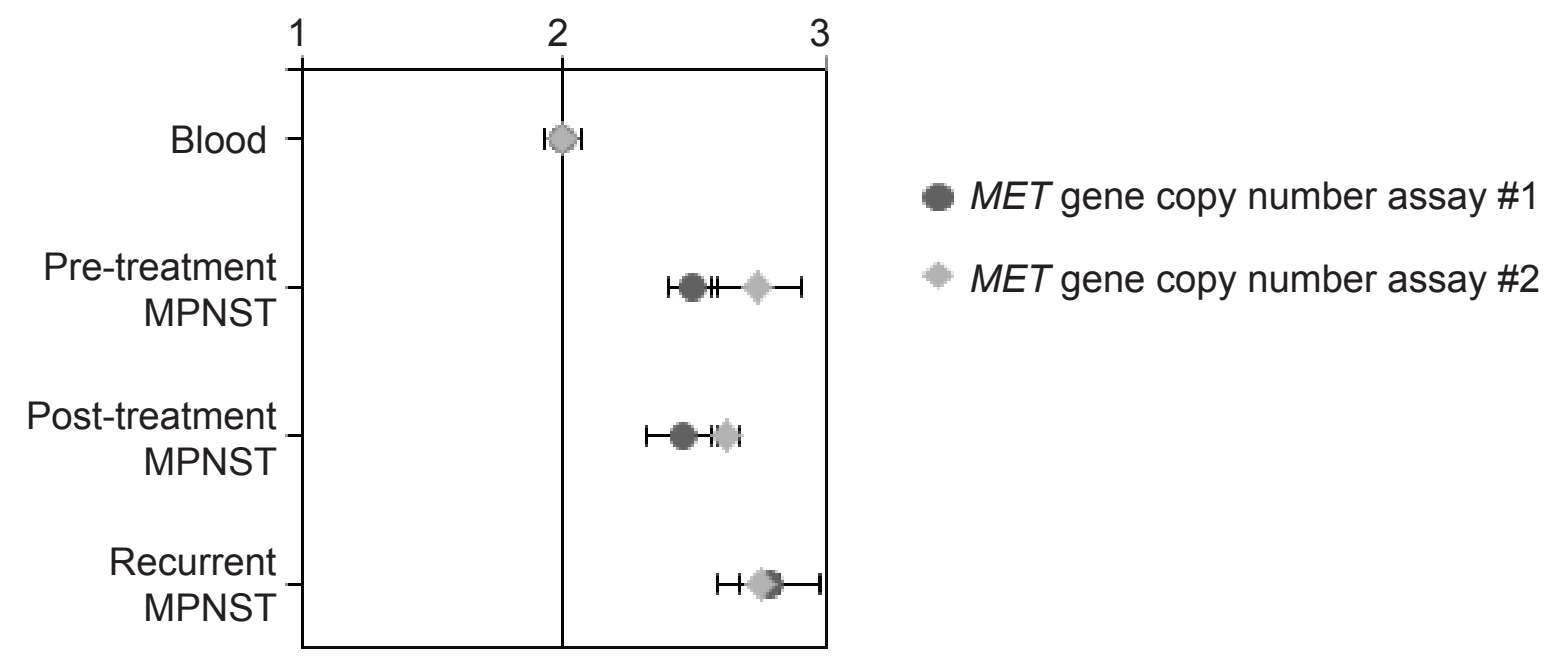

Supplemental Figure 1: Increase in MET copy number during MPNST progression. Copy number changes in MET were confirmed with quantitative polymerase chain reaction using two assays. Average copy number is reported relative to blood DNA (N=2). Error bars indicate the standard error from technical triplicates. 


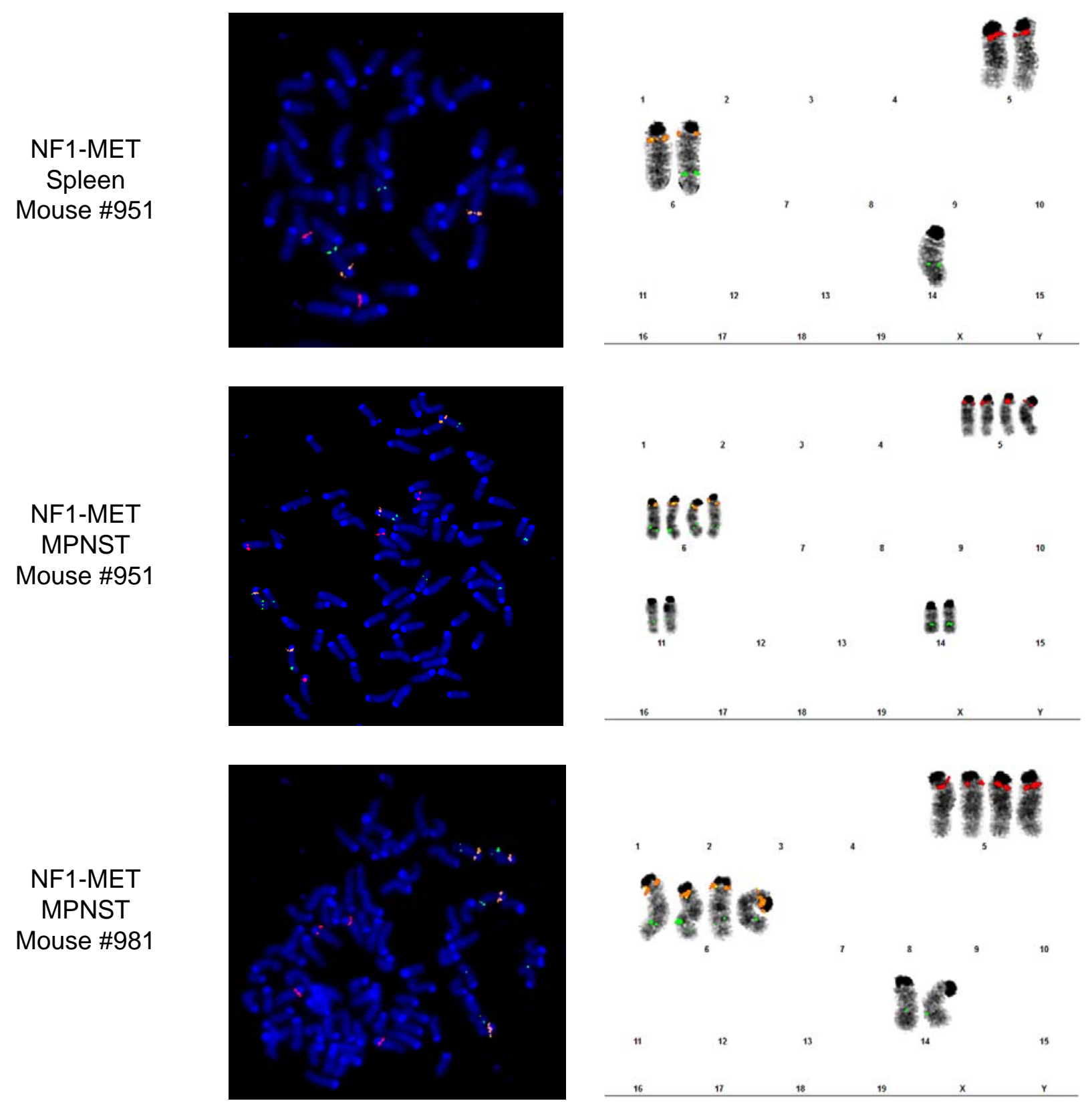

Supplemental Figure 2: Gene copy number analysis of the Met transgene and endogenous Met. Metaphase FISH was used to measure the R26-MET transgene copy numbers. FISH probes r26-MET plasmid green, 6A2-1 (mouse Met) orange, and 5A2-2 (mouse HGF) red were used on normal spleen and MPNSTs from NF1-MET mice. 


\begin{tabular}{|c|c|c|c|}
\hline Line & $\begin{array}{c}\text { Cox PH } \\
\text { Coefficient }\end{array}$ & SE & $\mathbf{P}$ \\
\hline$N F 1^{f / K O}$ & -2.3612 & 0.6489 & 0.0003 \\
\hline$N F 1^{f / /+} ; M E T ; C r e$ & -2.6354 & 0.7619 & 0.0005 \\
\hline NF $1^{\text {fiko }}$;Cre & -2.3409 & 0.7614 & 0.0021 \\
\hline$N F 1^{f / 4+}$ & -2.2420 & 0.5791 & 0.0001 \\
\hline
\end{tabular}

Supplemental Table 1: Cox Regression Analysis of Tumor-Free Survival. Results from testing for differences in tumor-free survival times between mouse lines. Mouse line $N F 1^{f / K O}$;MET;Cre was used as the reference group.

\begin{tabular}{|c|c|c|c|}
\hline Line & Estimate & SE & $\mathbf{P}$ \\
\hline NF1 ${ }^{\text {fliko }}$;MET;Cre & 0.8473 & 0.4879 & 0.0825 \\
\hline$N F 1^{\text {fl/kO }}$ & -3.1499 & 0.8876 & 0.0004 \\
\hline $\mathrm{NF}^{\mathrm{fl} / \mathrm{t}+\mathrm{MET} \text {; Cre }}$ & -3.0986 & 0.8891 & 0.0005 \\
\hline$N F 1^{\text {fliko }}$;Cre & -2.6799 & 0.7267 & 0.0002 \\
\hline $\mathrm{NF} 1^{\mathrm{fl//+}}$ & -2.6931 & 0.7900 & 0.0007 \\
\hline
\end{tabular}

Supplemental Table 2: Logistic Regression Analysis of Cause of Death Frequency. Results from testing for differences in the proportion of mice that had deaths related to tumor burden. 


\begin{tabular}{|c|c|c|c|}
\hline Sample & $\begin{array}{l}\text { \# of r26-MET } \\
\text { plasmid } \\
\text { FISH Signals }\end{array}$ & $\begin{array}{l}\text { r26-MET plasmid Integration Sites } \\
\text { (Approximation) }\end{array}$ & $\begin{array}{l}\text { Chr Count and } \\
\text { Ploidy Level }\end{array}$ \\
\hline $\begin{array}{l}\text { NF1-MET } \\
\text { spleen } \\
\text { Mouse \#951 }\end{array}$ & $\begin{array}{l}2[2] \\
3[16] \\
4[2]\end{array}$ & $\begin{array}{c}6 \mathrm{E}, 14 \mathrm{E} 1[2] \\
6 \mathrm{E}, 6 \mathrm{E}, 14 \mathrm{E} 1[13] / 6 \mathrm{E}, 11 \mathrm{~B} 5,14 \mathrm{E} 1[3] \\
6 \mathrm{E}, 6 \mathrm{E}, 11 \mathrm{~B} 5,14 \mathrm{E} 1[2]\end{array}$ & $40<2 n>[20]$ \\
\hline $\begin{array}{l}\text { NF1'MET } \\
\text { MPNST } \\
\text { Mouse \#951 }\end{array}$ & $\begin{array}{l}3[10] \\
4[6] \\
6[2] \\
8[2]\end{array}$ & $\begin{array}{c}6 \mathrm{E}, 6 \mathrm{E}, 14 \mathrm{E} 1[10] \\
6 \mathrm{E}, 6 \mathrm{E}, 6 \mathrm{E}, 14 \mathrm{E} 1[2] / 6 \mathrm{E}, 6 \mathrm{E}, 11 \mathrm{~B} 5,14 \mathrm{E} 1[4] \\
6 \mathrm{E}, 6 \mathrm{E}, 6 \mathrm{E}, 6 \mathrm{E}, 14 \mathrm{E} 1,14 \mathrm{E} 1[2] \\
6 \mathrm{E}, 6 \mathrm{E}, 6 \mathrm{E}, 6 \mathrm{E}, 11 \mathrm{~B} 5,11 \mathrm{~B} 5,14 \mathrm{E} 1,14 \mathrm{E} 1[2]\end{array}$ & $\begin{array}{r}39 \sim 40<2 n>[16] \\
79 \sim 80<4 n>[4]\end{array}$ \\
\hline $\begin{array}{l}\text { NF1-MET } \\
\text { MPNST } \\
\text { Mouse \#981 }\end{array}$ & $\begin{array}{l}2[1] \\
3[10] \\
4[3] \\
6[6]\end{array}$ & $\begin{array}{c}6 \mathrm{E}, 14 \mathrm{E} 1[1] \\
6 \mathrm{E}, 6 \mathrm{E}, 14 \mathrm{E} 1[10] \\
6 \mathrm{E}, 6 \mathrm{E}, 11 \mathrm{~B} 5,14 \mathrm{E} 1[3] \\
6 \mathrm{E}, 6 \mathrm{E}, 6 \mathrm{E}, 6 \mathrm{E}, 14 \mathrm{E} 1,14 \mathrm{E} 1[6]\end{array}$ & $\begin{array}{r}40 \sim 41<2 n>[14] \\
80 \sim 82<4 n>[6]\end{array}$ \\
\hline $\begin{array}{l}\text { NF1-MET } \\
\text { MPNST } \\
\text { Mouse \#981 } \\
\text { Xenograft }\end{array}$ & $\begin{array}{l}2[3] \\
3[16] \\
6[1]\end{array}$ & $\begin{array}{c}6 \mathrm{E}, 14 \mathrm{E} 1[1] / 6 \mathrm{E}, 6 \mathrm{E}[2] \\
6 \mathrm{E}, 6 \mathrm{E}, 14 \mathrm{E} 1[16] \\
6 \mathrm{E}, 6 \mathrm{E}, 6 \mathrm{E}, 6 \mathrm{E}, 14 \mathrm{E} 1,14 \mathrm{E} 1[1]\end{array}$ & $\begin{array}{c}40 \sim 42<2 n>[19] \\
82<4 n>[1]\end{array}$ \\
\hline
\end{tabular}

Supplemental Table 3: Summary of R26-MET transgene localization. Interphase FISH analysis spleen and MPNST cells from NF1-MET mice was performed and the r26-MET (green) signal was assessed. Note that several tumors had diploid and tetraploid cells present. 


\begin{tabular}{|c|c|c|c|c|c|c|c|c|}
\hline Chromosome & $6 A 2 / 5 A 2$ & 6A2/5A2 & 6A2/5A2 & 6A2/5A2 & 6A2/5A2 & 6A2/5A2 & 6A2/5A2 & Total \\
\hline \# of FISH signals & 2O/2R & 2O/3R & 3O/2R & $40 / 2 R$ & $60 / 2 R$ & 6O/4R & 8O/4R & Counted \\
\hline \multicolumn{9}{|l|}{ Sample } \\
\hline $\begin{array}{c}\text { NF1-MET } \\
\text { MPNST } \\
\text { Mouse \#981 }\end{array}$ & $100.0 \%$ & - & - & - & - & - & - & 200 \\
\hline $\begin{array}{c}\text { NF1 } \\
\text { MPNST } \\
\text { Mouse \#986 }\end{array}$ & $87.5 \%$ & $12.5 \%$ & - & - & - & - & - & 200 \\
\hline $\begin{array}{c}\text { NF1-P53 } \\
\text { MPNST } \\
\text { Mouse\#7900 }\end{array}$ & $32.5 \%$ & - & $4.0 \%$ & $49.5 \%$ & $3.0 \%$ & $5.0 \%$ & $6.0 \%$ & 200 \\
\hline
\end{tabular}

Supplemental Table 4: Copy number analysis of Met and $\mathbf{H g f}$ in murine MPNST models. Relative copy number of Met and HGF was measured using dual-color interphase FISH on tumor touch preps from NF1-MET, NF1-P53, and NF1 MPNSTs. A summary of the FISH signals for the 6A2-1 and 6A2-2 (mouse Met) orange, and 5A2-2 (mouse Hgf) red is shown. 


\begin{tabular}{|c|c|c|c|c|c|c|}
\hline Line & Comparison & $\begin{array}{c}\text { Estimated } \\
\text { Difference in } \\
\text { Tumor } \\
\text { Growth Rates }\end{array}$ & Std Error & FDR q Value & $\begin{array}{c}95 \% \text { FCI } \\
\text { Lower }\end{array}$ & $\begin{array}{c}\text { 95\% FCI } \\
\text { Upper }\end{array}$ \\
\hline \multirow[t]{6}{*}{ NF1-MET } & Vehicle v 3 mg $/ \mathrm{kg}$ & 54.289 & 14.191 & 0.000 & 78.863 & 29.715 \\
\hline & Vehicle v $10 \mathrm{mg} / \mathrm{kg}$ & 110.422 & 14.191 & 0.000 & 134.996 & 85.848 \\
\hline & Vehicle v $30 \mathrm{mg} / \mathrm{kg}$ & 109.252 & 14.309 & 0.000 & 134.030 & 84.474 \\
\hline & 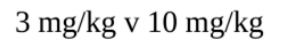 & 56.133 & 12.781 & 0.000 & 78.265 & 34.000 \\
\hline & $3 \mathrm{mg} / \mathrm{kg}$ v $30 \mathrm{mg} / \mathrm{kg}$ & 54.963 & 12.912 & 0.000 & 77.322 & 32.604 \\
\hline & 10 mg/kg v 30 mg/kg & -1.169 & 12.912 & 0.928 & 21.189 & -23.528 \\
\hline \multirow[t]{6}{*}{ NF1 } & Vehicle v 3 mg/kg & 0.968 & 4.124 & 0.901 & 11.848 & -9.913 \\
\hline & Vehicle v $10 \mathrm{mg} / \mathrm{kg}$ & -0.512 & 4.124 & 0.901 & 10.368 & -11.392 \\
\hline & Vehicle v $30 \mathrm{mg} / \mathrm{kg}$ & 9.559 & 4.125 & 0.061 & 20.442 & -1.324 \\
\hline & $3 \mathrm{mg} / \mathrm{kg}$ v $10 \mathrm{mg} / \mathrm{kg}$ & -1.480 & 4.222 & 0.901 & 9.659 & -12.619 \\
\hline & 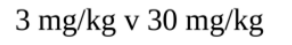 & 8.591 & 4.223 & 0.084 & 19.733 & -2.551 \\
\hline & $10 \mathrm{mg} / \mathrm{kg}$ v $30 \mathrm{mg} / \mathrm{kg}$ & 10.071 & 4.223 & 0.061 & 21.212 & -1.070 \\
\hline \multirow[t]{6}{*}{ NF1-P53 } & Vehicle v 3 mg/kg & -28.651 & 35.730 & 0.513 & 65.614 & -122.916 \\
\hline & Vehicle v $10 \mathrm{mg} / \mathrm{kg}$ & -0.187 & 35.857 & 0.996 & 94.413 & -94.787 \\
\hline & Vehicle v $30 \mathrm{mg} / \mathrm{kg}$ & 32.346 & 35.600 & 0.513 & 126.267 & -61.575 \\
\hline & $3 \mathrm{mg} / \mathrm{kg}$ v $10 \mathrm{mg} / \mathrm{kg}$ & 28.464 & 35.860 & 0.513 & 123.072 & -66.145 \\
\hline & 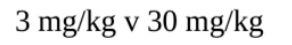 & 60.997 & 35.603 & 0.513 & 154.926 & -32.932 \\
\hline & $10 \mathrm{mg} / \mathrm{kg}$ v $30 \mathrm{mg} / \mathrm{kg}$ & 32.533 & 35.730 & 0.513 & 126.799 & -61.732 \\
\hline
\end{tabular}

\section{Supplementary Table 5: Linear Mixed-Effects Modeling of Tumorgraft Results.}

Results of linear mixed-effects models, by line, which were used to estimate and identify differences in tumor growth rates. FDR $q$ is the false-discovery rate $q$ value (i.e. adjusted $p$ value). $\mathrm{FCl}$ stands for false coverage interval and is the false-discovery rate adjusted analog to a confidence interval. 


\begin{tabular}{lccc}
\hline Line & $\begin{array}{c}\text { Estimated Percent } \\
\text { Reduction }\end{array}$ & $\begin{array}{c}\text { Bootstrap 2.5 } \\
\text { Percentile }\end{array}$ & $\begin{array}{c}\text { Bootstrap 97.5 } \\
\text { Percentile }\end{array}$ \\
NF1-MET & $88.09 \%$ & $72.70 \%$ & $102.72 \%$ \\
NF1 & $34.87 \%$ & $7.62 \%$ & $58.16 \%$ \\
NF1-P53 & $14.98 \%$ & $0.88 \%$ & $42.31 \%$ \\
\hline
\end{tabular}

Supplementary Table 6: Bootstrap Resampling Results on Percent Reduction in Tumor Growth. 10,000 datasets were created via non-parametric bootstrap resampling. The ratio of the estimated tumor growth rate of Capmatinib $30 \mathrm{mg} / \mathrm{kg}$ and vehicle was calculated based on each of the 10,000 datasets. The $2.5^{\text {th }}$ and $97.5^{\text {th }}$ percentiles are the respective percentiles of the estimated ratios from the 10,000 datasets. An '*' denotes non-overlapping bootstrap percentile intervals. 
bioRxiv preprint doi: https://doi.org/10.1101/199000; this version posted October 5, 2017. The copyright holder for this preprint (which was not

Figure 1 certified by peer review) is the author/funder. All rights reserved. No reuse allowed without permission.
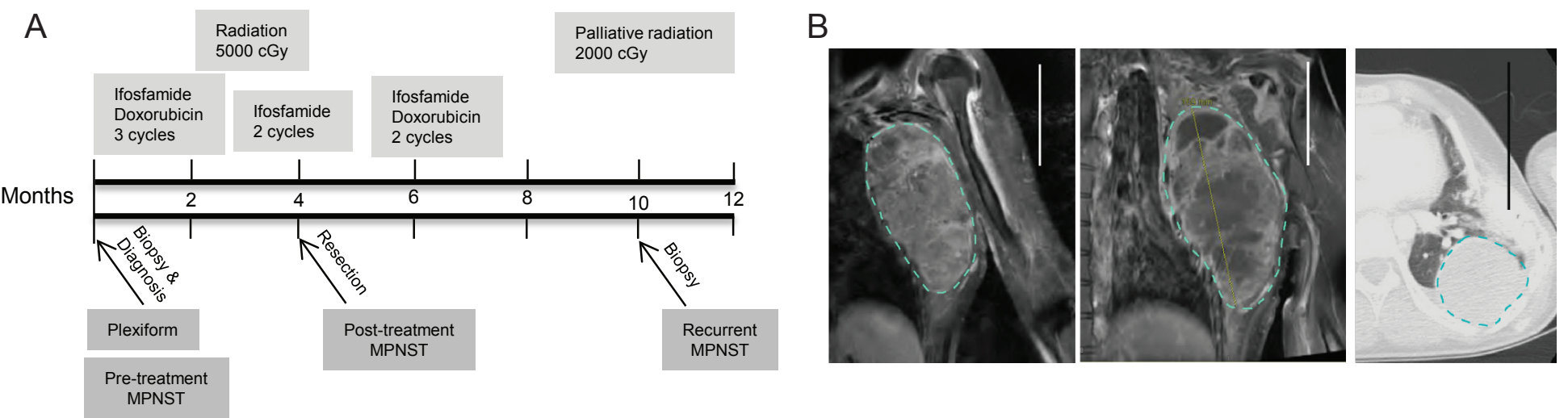

C
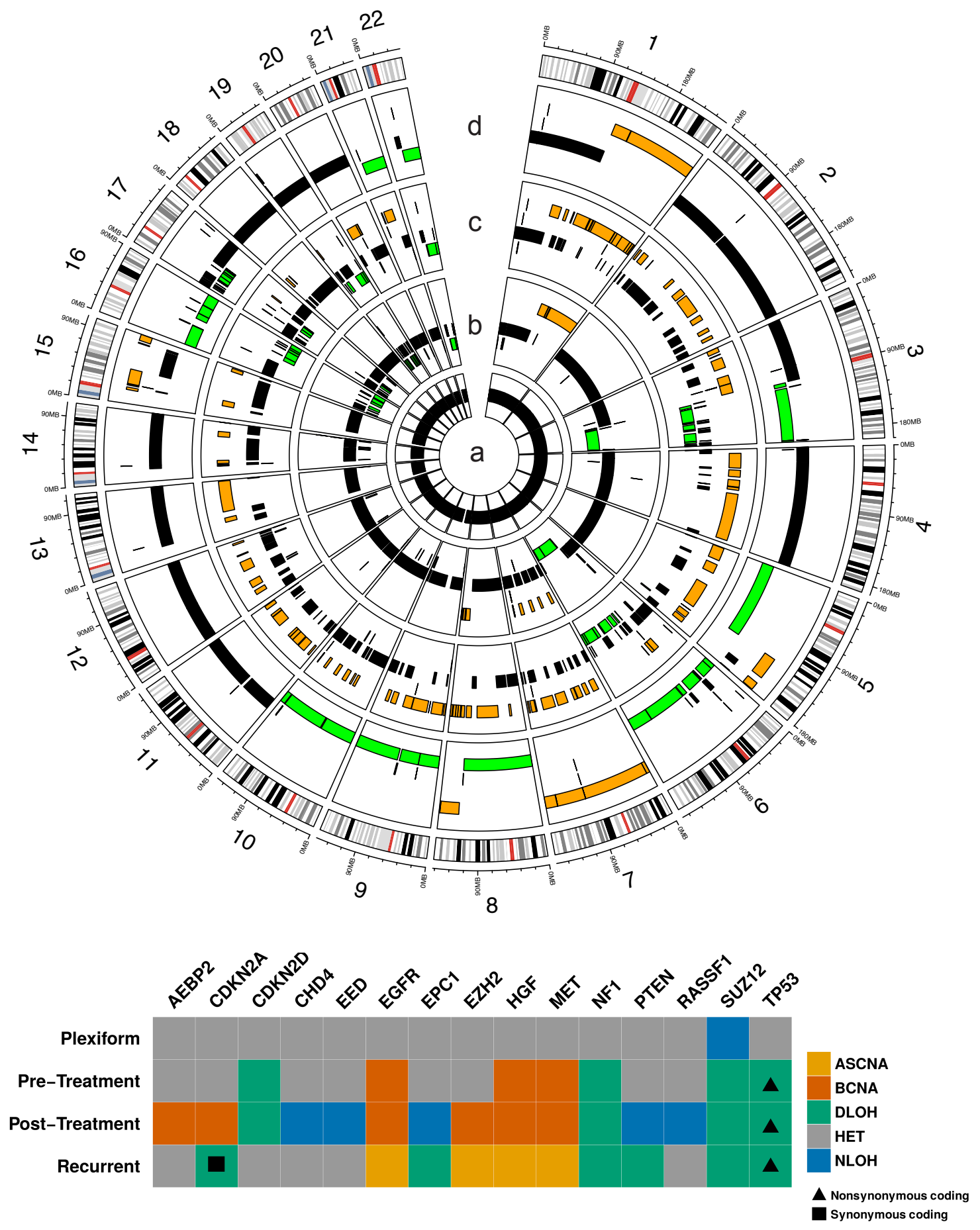
bioRxiv preprint doi: https://doi.org/10.1101/199000; this version posted October 5, 2017. The copyright holder for this preprint (which was not certified by peer review) is the author/funder. All rights reserved. No reuse allowed without permission.

Figure 2
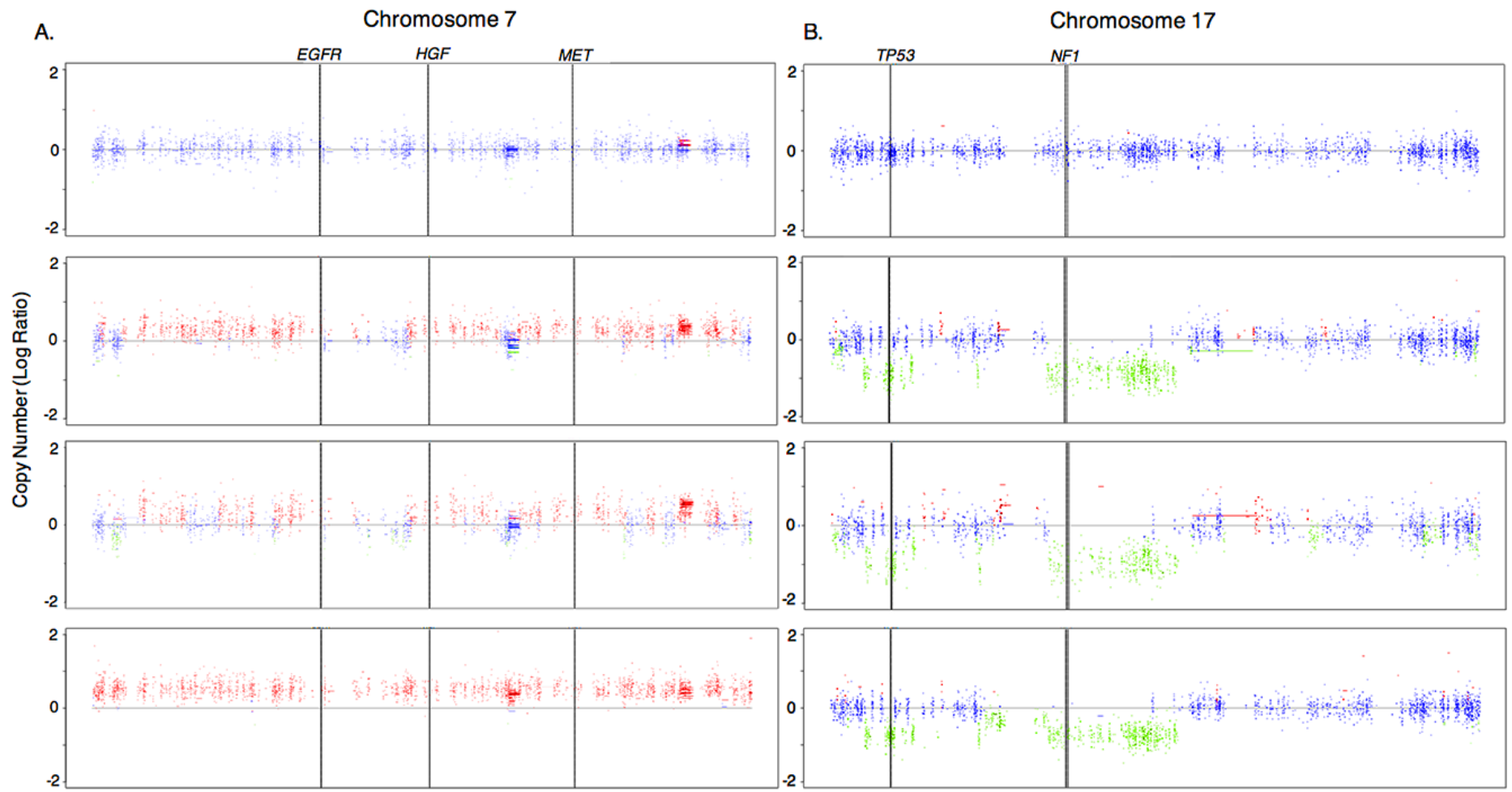
bioRxiv preprint doi: https://doi.org/10.1101/199000; this version posted October 5, 2017. The copyright holder for this preprint (which was not certified by peer review) is the author/funder. All rights reserved. No reuse allowed without permission.

Figure 3

A

$$
\begin{aligned}
& \text { NF1 } 1^{\text {fI/KO }} \text {;lox-stop-loxMET } T^{\mathrm{tg} /+} \text {; } \\
& \quad \text { PIp1-CRE/ERT }
\end{aligned}
$$

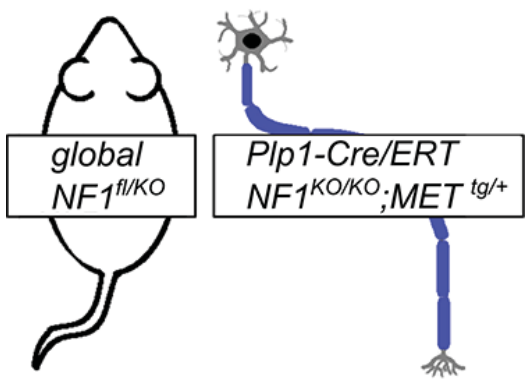

C

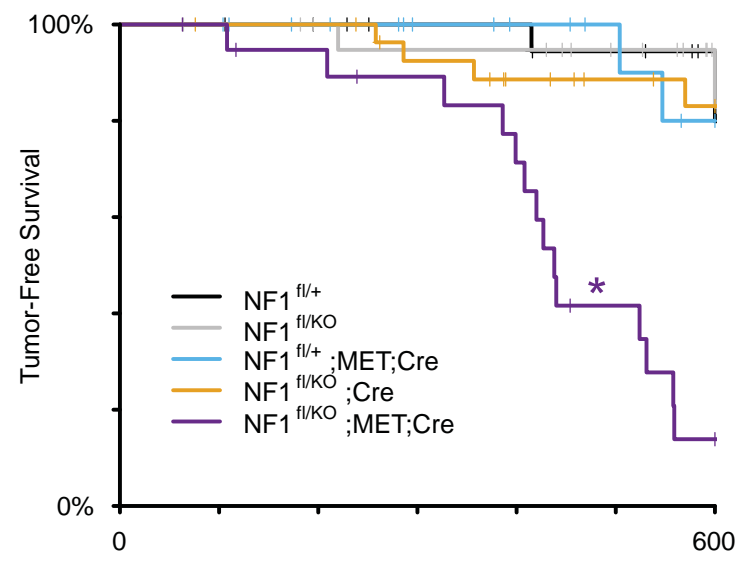

Days
B

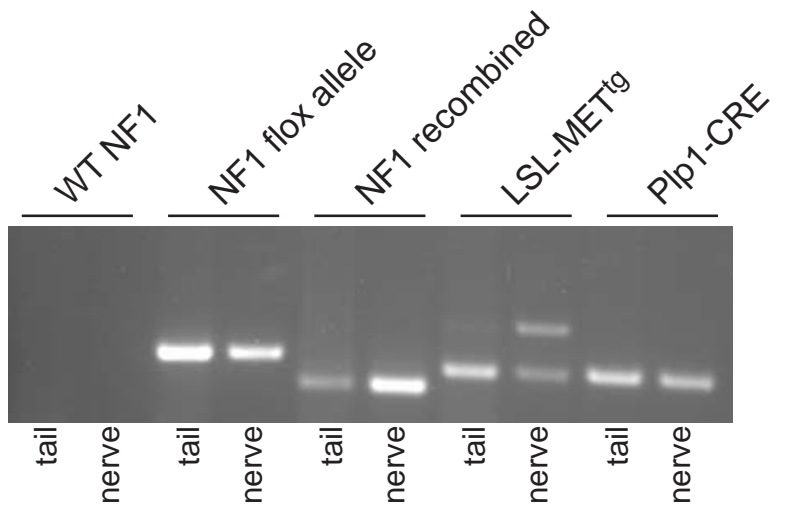

D

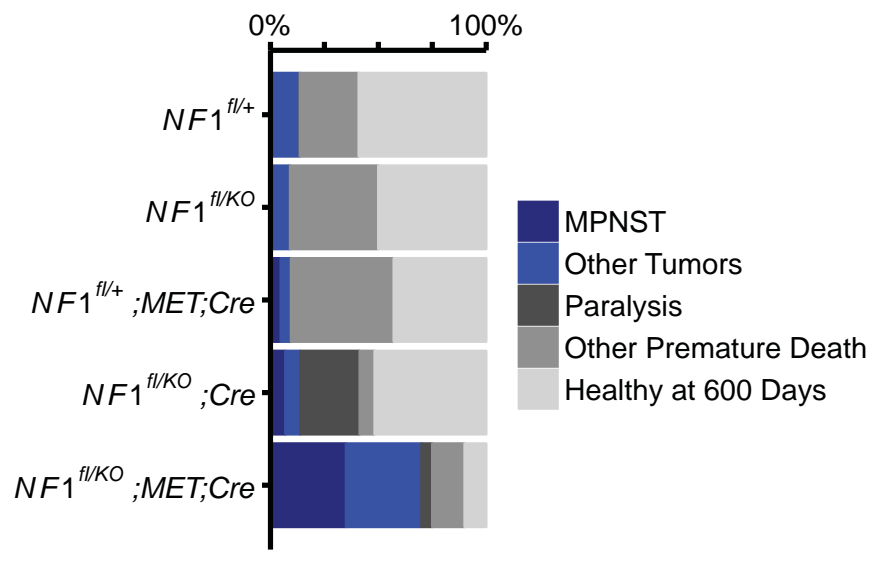

$E$

$H \& E$

Ki67

pMET

pERK

pS6
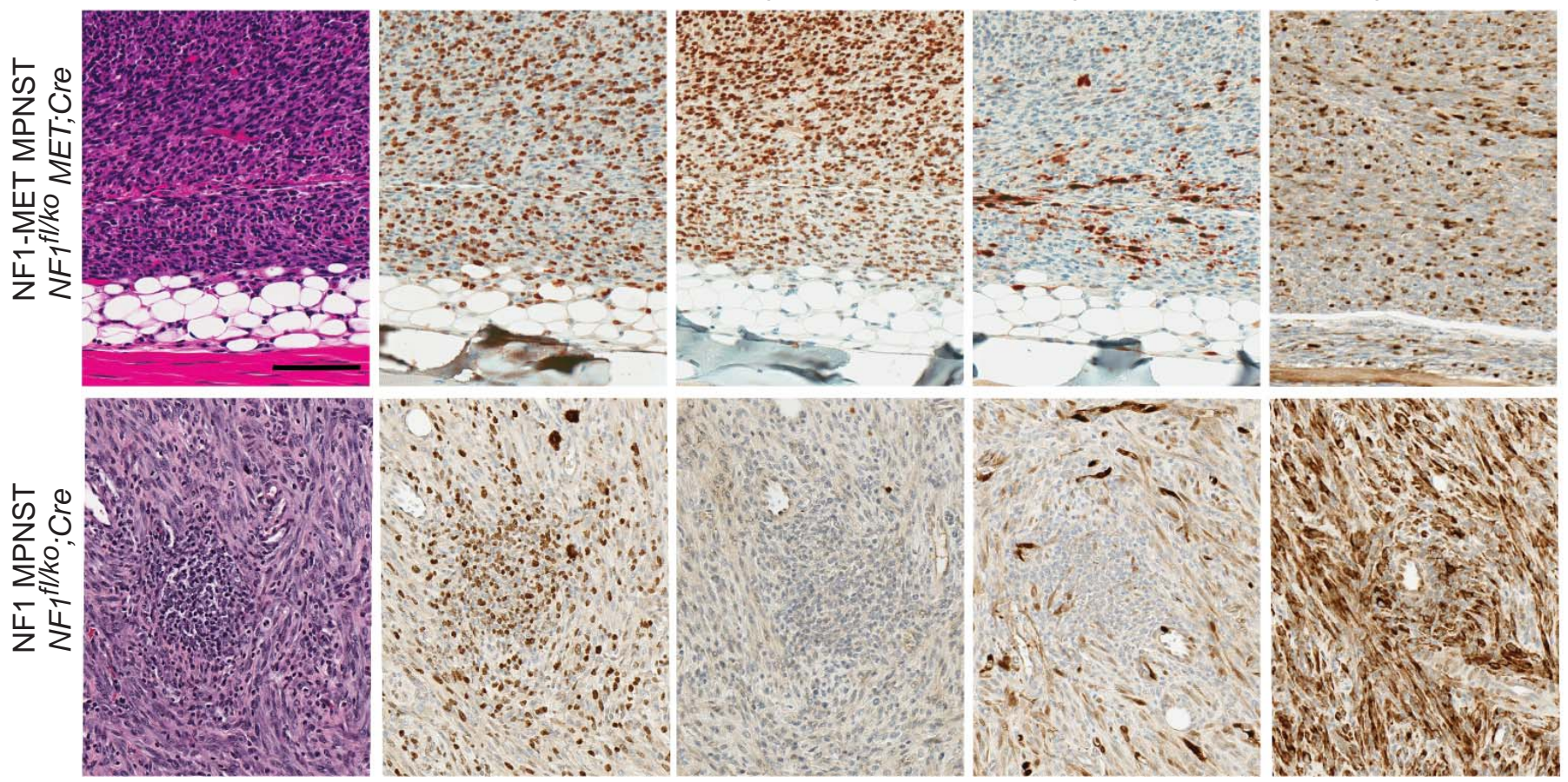
bioRxiv preprint doi: https://doi.org/10.1101/199000; this version posted October 5, 2017. The copyright holder for this preprint (which was not certified by peer review) is the author/funder. All rights reserved. No reuse allowed without permission.

Figure 4

A

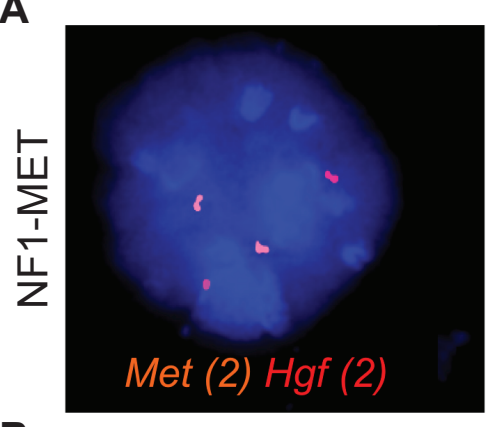

B

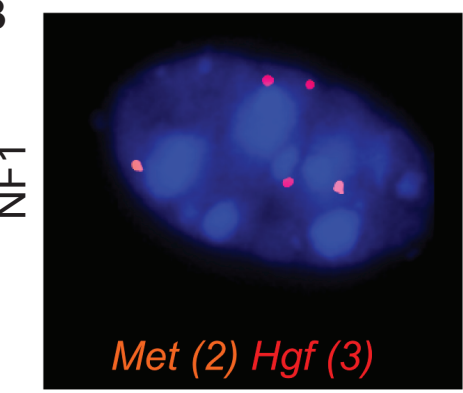

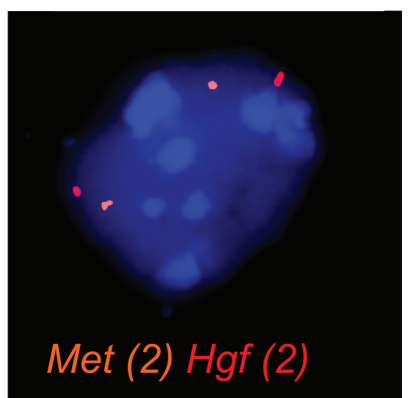

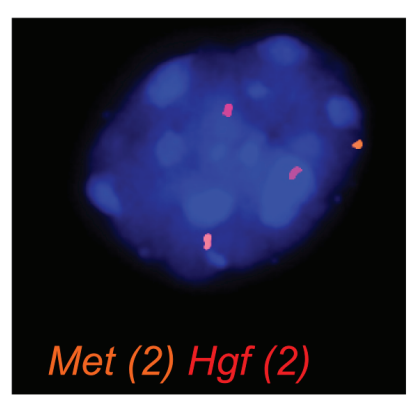

C
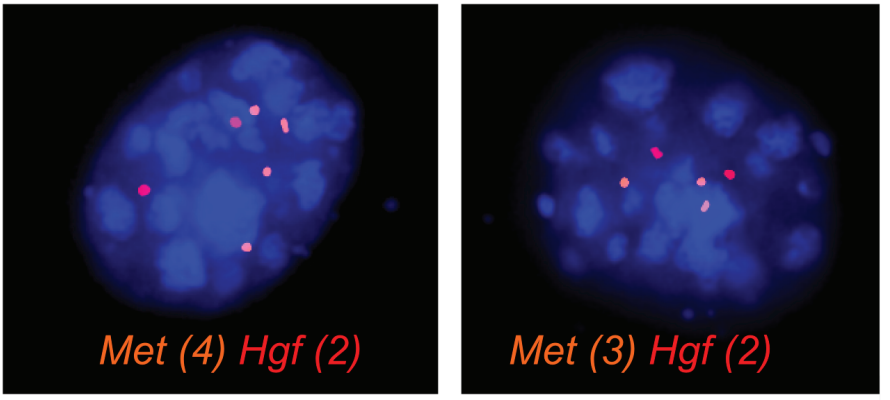

穵

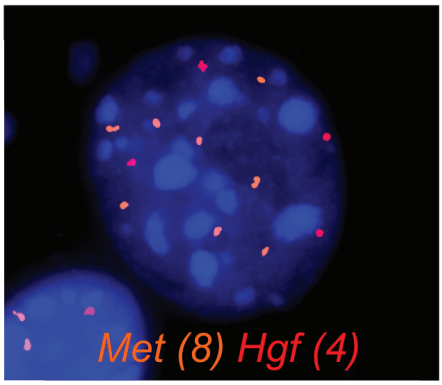




\section{Figure 5} certified by peer review) is the author/funder. All rights reserved. No reuse allowed without permission.

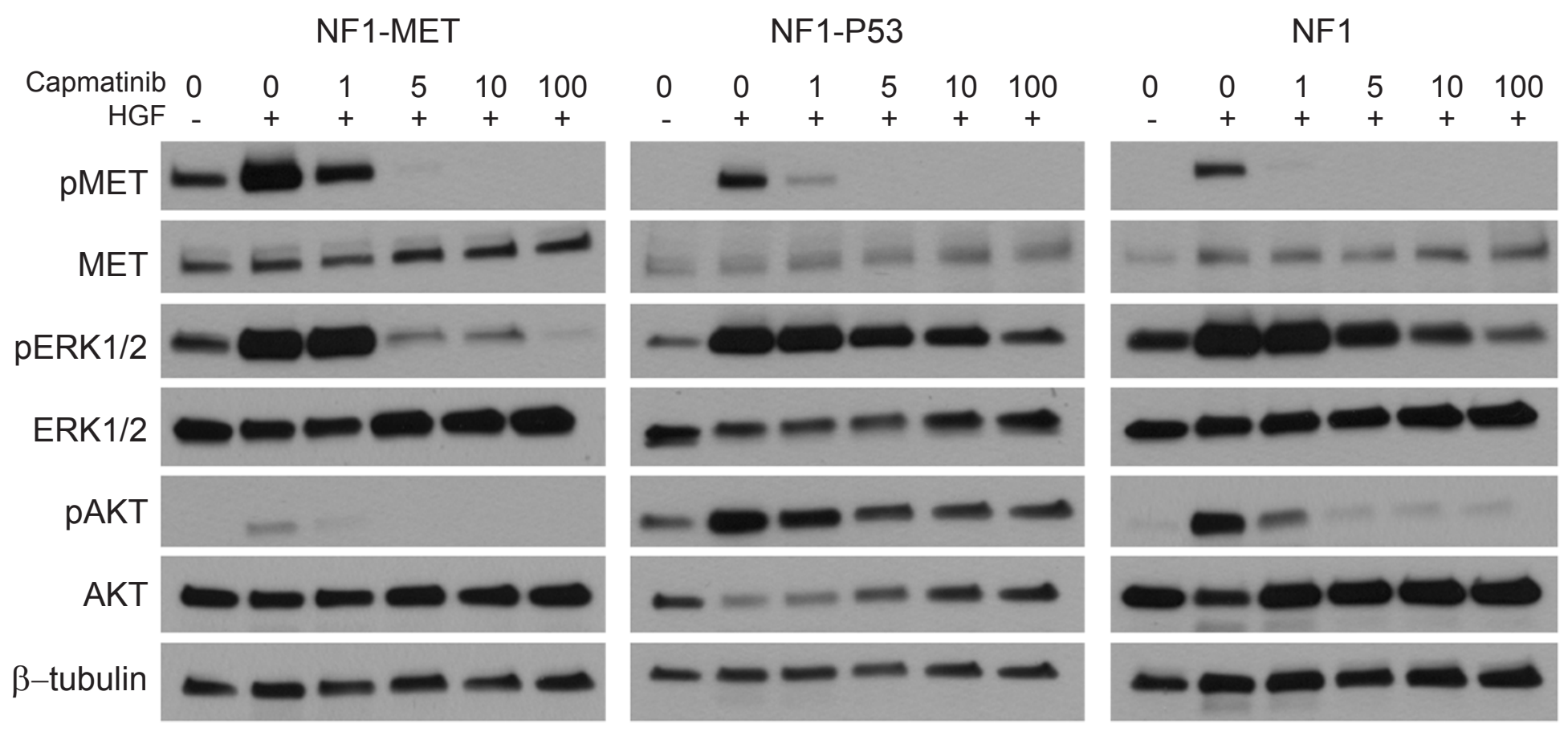




\section{Figure 6}

A
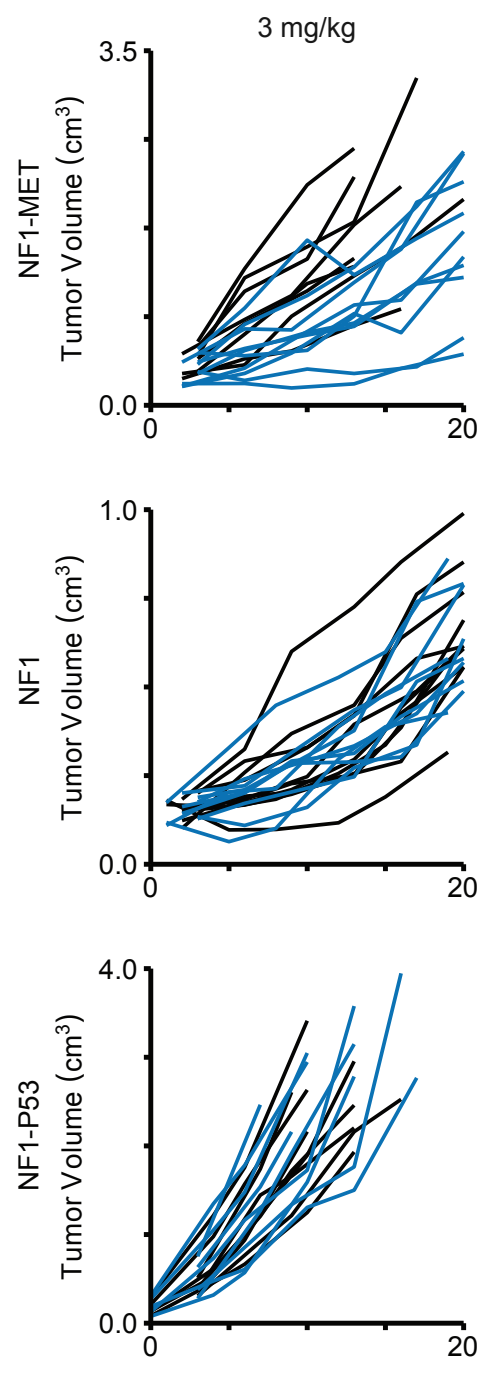

C

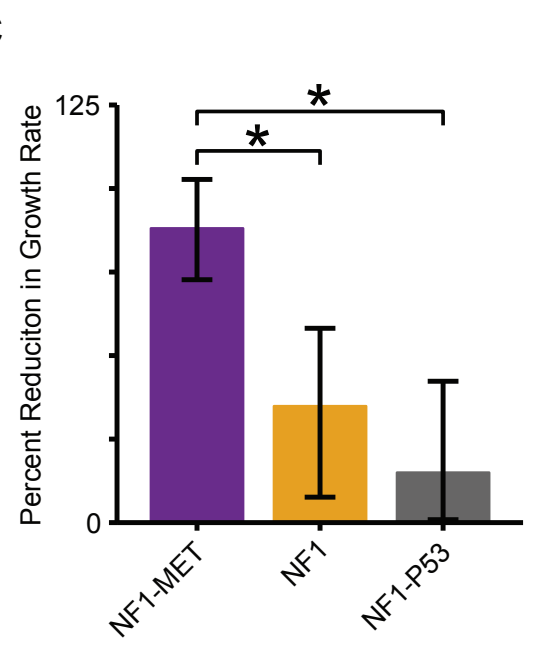

\section{Capmatinib}
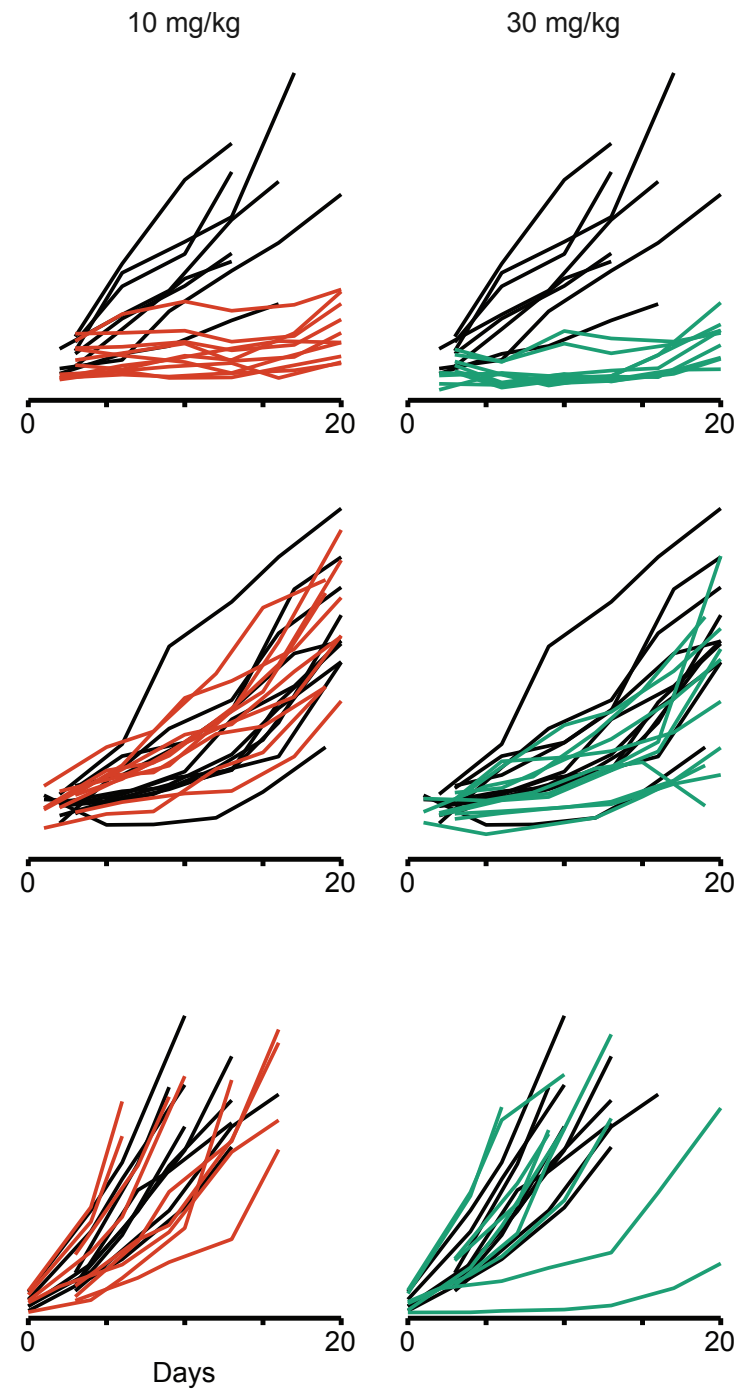

B
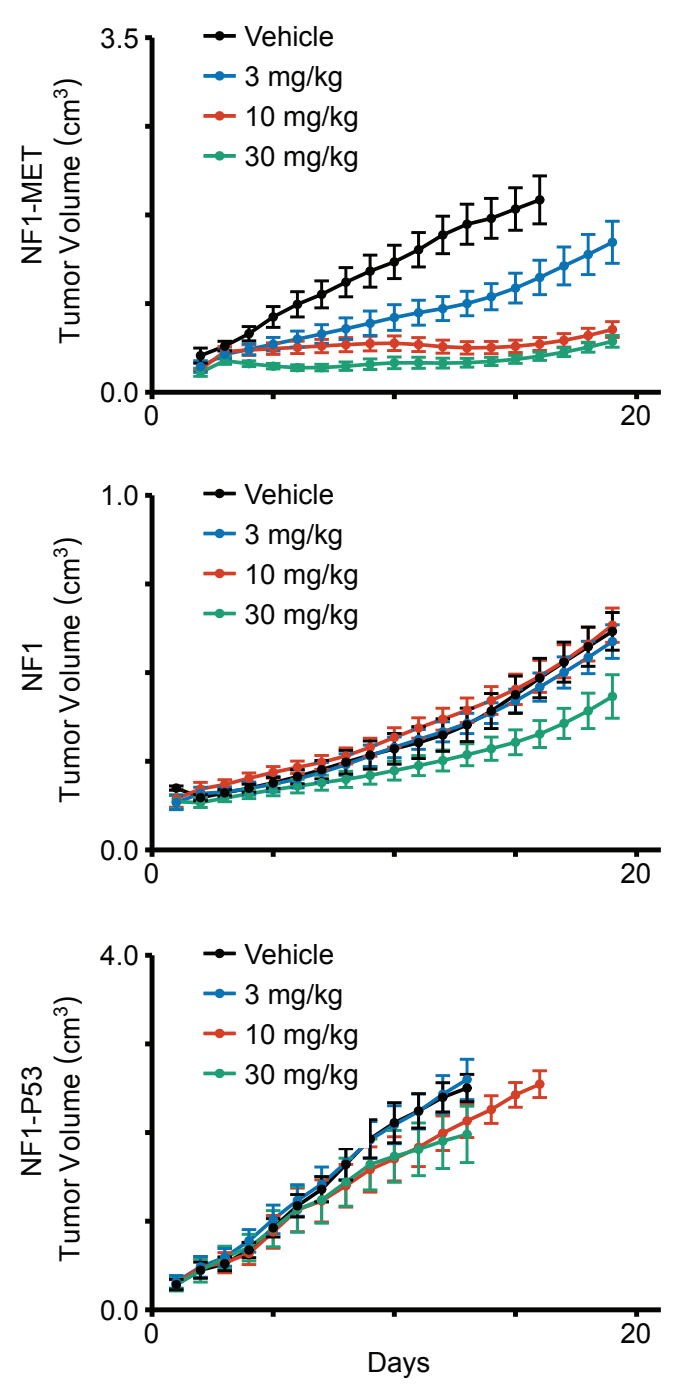

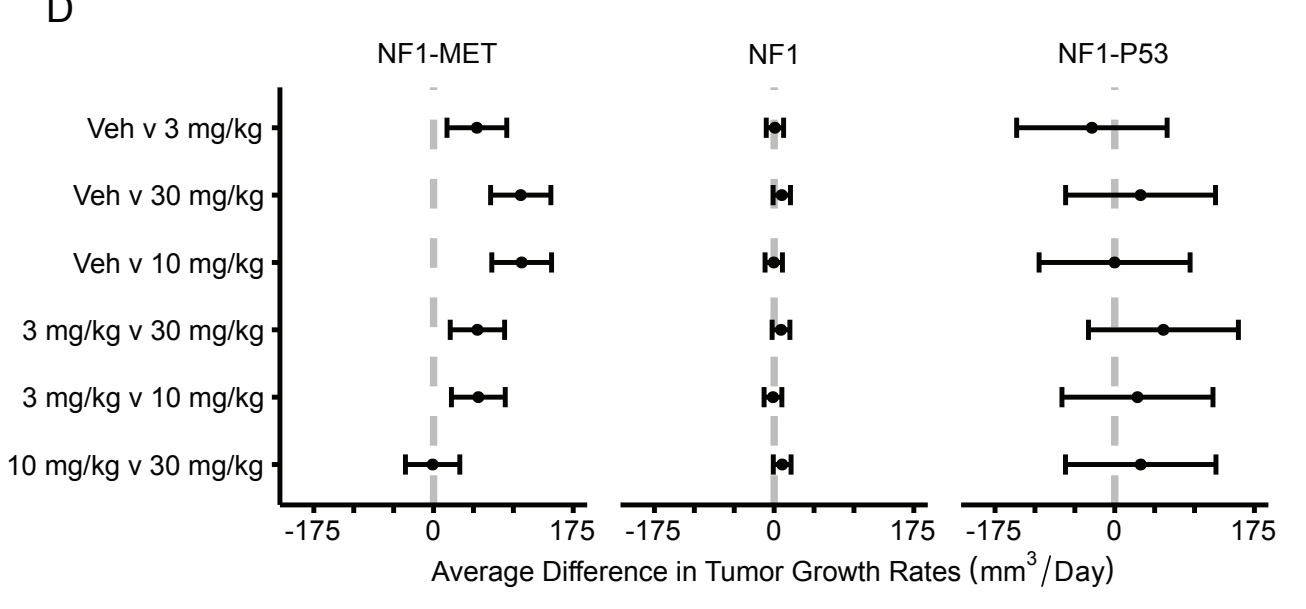

